LRRI-19990901

PNNL-13053

\title{
INDEPENDENT EVALUATION OF AIR FILTER MEDIA
}

\author{
FROM CHORNOBYL
}

\author{
September 10, 1999 \\ Mark D. Hoover, PhD, CHP, CIH \\ and Alice F. Fencl \\ Lovelace Respiratory Research Institute \\ P.O. Box 5890 \\ Albuquerque, NM 87185-5890 \\ Phone: 505-845-1040; Fax: 505-845-1180 \\ mhoover@LRRI.org \\ and \\ George J. Vargo, PhD., CHP \\ International Nuclear Safety Program \\ Pacific Northwest National Laboratory \\ Phone: 509-375-6836; Fax: 509-375-2019 (fax) \\ vargo@pnl.gov

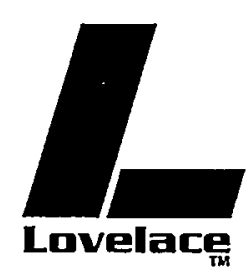

\section{LOVELACE RESPIRATORY RESEARCH INSTITUTE}

P.O. Box 5890

Albuquerque, NM 87185-5890

Research performed for the U.S. Department of Energy under Cooperative Agreement DE-FC04-96AL76406 



\section{DISCLAIMER}

This report was prepared as an account of work sponsored by an agency of the United States Government. Neither the United States Government nor any agency thereof, nor any of their employees, make any warranty, express or implied, or assumes any legal liability or responsibility for the accuracy, completeness, or usefulness of any information, apparatus, product, or process disclosed, or represents that its use would not infringe privately owned rights. Reference herein to any specific commercial product, process, or service by trade name, trademark, manufacturer, or otherwise does not necessarily constitute or imply its endorsement, recommendation, or favoring by the United States Government or any agency thereof. The views and opinions of authors expressed herein do not necessarily state or reflect those of the United States Government or any agency thereof. 


\section{DISCLAIMER}

Portions of this document may be illegible in electronic image products. Images are produced from the best available original document. 
Table of Contents

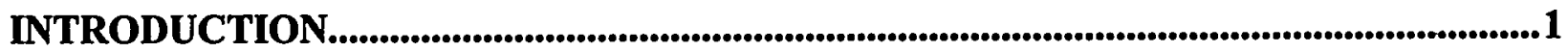

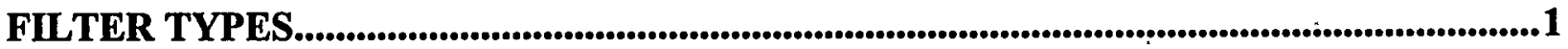

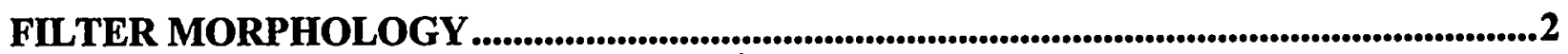

AFA-RMP-20 FilterS.................................................................................................................2

Gauze-Front Lepestok Mask ..................................................................................................2

Fiber-Front Lepestok Mask....................................................................................................2

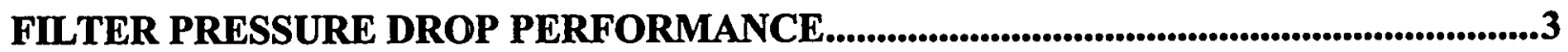

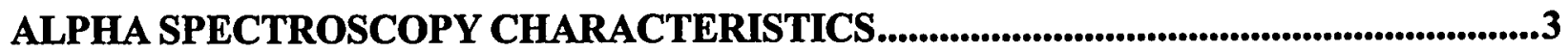

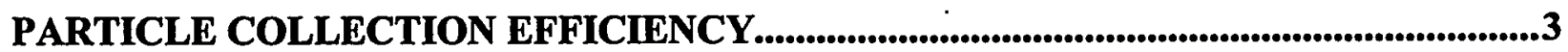

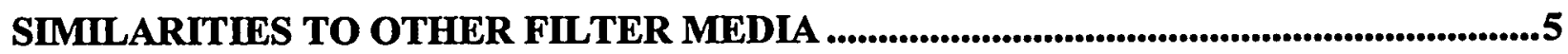

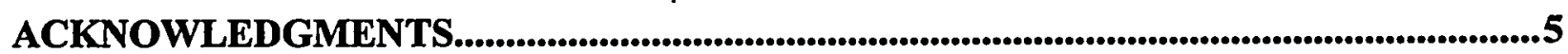

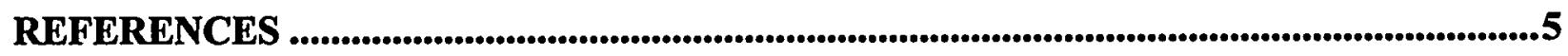

APPENDIX A: DATA CERTIFICATE FOR AFA-RSP ANALYTICAL FILTERS .......... A1 APPENDIX B: CHARACTERISTICS OF FLTERS EVALUATED FOR USE IN SAMPLING RADIOACTIVE PARTICLES ..................................................................... B1 


\section{List of Figures}

Figure 1 View of the two cartons of AFA-RMP-20 filters provided for testing. The manufacturer's labels are shown in the original position on the carton marked with the letter "alpha" and detached from the carton marked with the letter "beta".

Figure 2 View of an open carton of AFA-RMP-20 filters, with an individual paper holder of filters removed from the carton. Each paper holder is secured with a rubber band and contains 10 filters. There are 10 holders per carton.

Figure 3 View of an open paper filter holder with two of the AFA-RMP-20 filters removed. Each filter consists of a filter element in the form of a disk. The backside of the filter element has a gauze support mesh. The collection side of the filter disk is glued to a white paper support ring with a projecting handle. Each filter has a removable, protective brown paper ring with a projecting handle. The filter on the left has the protective rings in place and the filter on the right has the protective rings removed.

ure 4 Schematic diagram of the AFA-RMP-20 filter assembly (not to scale) showing the relative positions of the paper support ring and handle, the fiber filter collection layer, and the gauze backing layer. The brown paper protective ring is not shown.

Figure 5 Closer view of an AFA-RMP-20 filter with its protective brown paper ring.................. 10

Figure 6 Closer view of an AFA-RMP-20 filter with its protective rings removed. The white paper support ring and handle can be seen glued on the top surface of the filter itself........11

Figure 7 View of the collection side of an AFA-RMP-20 filter. The paper support ring with a projection for handling the filter is glued to the collection side of the filter.........................12

Figure 8 Scanning electron photomicrograph of the collection surface of an AFA-RMP-20 fibertype analytical filter. (Magnification is 37X. Scale factor is $27 \mu \mathrm{m} / \mathrm{mm}$. The width of the visible image is $4.5 \mathrm{~mm}$.) The typical fiber diameters are on the order of $1 \mu \mathrm{m}$. Typical fiber lengths are on the order of millimeters.

Figure 9 View of the gauze support mesh on the backside of an AFA-RMP-20 filter................14

Figure 10 Scanning electron photomicrograph of the gauze support side (backside) of an AFARMP-20 fiber-type analytical filter. (Magnification is 37X. Scale factor is $27 \mu \mathrm{m} / \mathrm{mm}$. The width of the visible image is $4.5 \mathrm{~mm}$.) The typical diameter of the thread bundles of the gauze is about $0.3 \mathrm{~mm}$. The typical diameter of the individual threads in the gauze fiber bundles is about $10 \mu \mathrm{m}$.

Figure 11 Higher magnification scanning electron photomicrograph of the gauze support side (back side) of an AFA-RMP-20 fiber-type analytical filter. (Magnification is 370X. Scale factor is $2.7 \mu \mathrm{m} / \mathrm{mm}$. The width of the visible image is $0.45 \mathrm{~mm}$.) The fiber matrix of the collection filter is more clearly visible in the background.

Figure 12 View of a "gauze-front" Lepestok facemask being worn by an adult male. A soft metal clip in the top edge of the mask holds the mask on the bridge of the nose. A pair of elastic cords in the bottom edge of the mask pull the mask into a bunched shape under the chin. Two cloth ties attached to the central edges of the mask are tied behind the neck to secure the mask on the face. A star-shaped plastic frame on the inside of the mask helps retain a proper shape of the mask over the mouth area. The "fiber-front" Lepestok face mask has a similar appearance when worn......................................................................17 17

Figure 13 Schematic diagram of the construction of the "gauze-front" Lepestok facemask. The filter layer is supported on the front and back sides by gauze. The gauze layers and the 
filter layer are similar to the gauze and filter materials used in the AFA-RMP-20 fiber-type analytical filter. 18

Figure 14 Side view of a Lepestok facemask being worn by an adult male. Note how the internal metal clip at the top of the mask positions the mask on the bridge of the nose and how the elastic cords on the bottom edges of the mask pull the mask into position under the chin. 19

Figure 15 View of a package of the "gauze-front" Lepestok face masks. 20

Figure 16 View of the collection side of a "gauze-front" Lepestok filter. The ends of the cloth ties are visible at the left and right edges of the mask.

Figure 17 View of the back (face) side of the "gauze-front" Lepestok facemask. The area of the soft metal clip is located at the top edge of the mask. The ends of the elastic pull cords can be seen at the bottom edge of the mask. The star-shaped plastic frame is visible at the center of the mask. The cloth ties are folded over the center area.

Figure 18 Closer view of the back side of a "gauze-front" Lepestok face mask showing the region where the plastic support frame and the cloth ties are attached to the edge of the mask. The folded material at the edge shows the fine-fiber nature of the collection filter where the front surface of the filter is folded over onto the back side.

Figure 19 Scanning electron photomicrograph of the aerosol collection side of the "gauzefront" Lepestok face masks. (Magnification is 37X. Scale factor is $27 \mu \mathrm{m} / \mathrm{mm}$. The width of the visible image is $4.5 \mathrm{~mm}$.) The typical diameter of the thread bundles of the gauze is about $0.3 \mathrm{~mm}$. The typical diameter of the individual threads in the gauze fiber bundles is about $10 \mu \mathrm{m}$. Note that the distance between gauze fiber bundles is irregular.

Figure 20 Higher magnification scanning electron photomicrograph of a gauze mesh fiber bundle and the underlying fine-fiber filter matrix on the aerosol collection side of a "gauzefront" Lepestok face mask. (Magnification is 370X. Scale factor is $2.7 \mu \mathrm{m} / \mathrm{mm}$. The width of the visible image is $0.45 \mathrm{~mm}$.) The fine-fiber filter is similar in appearance to the AFA-RMP-20 filter material.

Figure 21 Scanning electron photomicrograph of the gauze support side (backside) of a "gauze-front" Lepestok face mask. (Magnification is 37X. Scale factor is $27 \mu \mathrm{m} / \mathrm{mm}$. The width of the visible image is $4.5 \mathrm{~mm}$.) In the samples examined in this study, the gauze mesh was more uniform on the backside of the facemask than on the front side.

Figure 22 Higher magnification scanning electron photomicrograph of the back (or face-) side of a "gauze-front" Lepestok face mask, showing both the gauze support mesh and the underlying fine-fiber aerosol collection filter. (Magnification is 370X. Scale factor is 2.7 $\mu \mathrm{m} / \mathrm{mm}$. The width of the visible image is $0.45 \mathrm{~mm}$.).

Figure 23 Scanning electron photomicrograph of the fine-fiber aerosol collection filter surface (without the gauze support mesh) on the back or face-side of a "gauze-front" Lepestok face mask. (Magnification is 370X. Scale factor is $2.7 \mu \mathrm{m} / \mathrm{mm}$. The width of the visible image

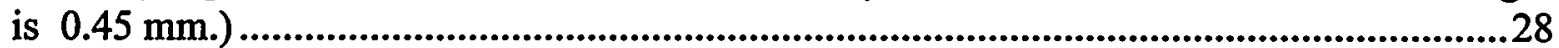

Figure 24 View of a package of "fiber-front" Lepestok face masks.........................................29

Figure 25 Schematic diagram of the construction of the "fiber-front" Lepestok facemask. The filter layer is protected on the front side by a coarse fiber filter media and supported on the backside by gauze. The gauze layer and filter layer are similar to the gauze and filter materials used in the AFA-RMP-20 fiber-type analytical filter. 
Figure 26 View of the front of a "fiber-front" Lepestok facemask. Note that the cloth tie feature is a single, continuous strip of cloth that is mounted between the front prefilter layer and the collection filter layer.

Figure 27 View of the face side of the "fiber-front" Lepestok facemask. The nose clip is located in the lower edge, the elastic pulls are located in the top edges, and the plastic frame and the neck ties are seen at the center.

Figure 28 View of the "fiber-front" Lepestok facemask ready for adjusting and attaching to the face. 33

Figure 29 View of the backside of a "fiber-front" Lepestok facemask, showing the elastic pull cords. 34

Figure 30 Low magnification scanning electron photomicrograph of the aerosol collection side of the "fiber-front" Lepestok facemask. (Magnification is 37X. Scale factor is $27 \mu \mathrm{m} / \mathrm{mm}$. The width of the visible image is $4.5 \mathrm{~mm}$.) The typical diameter of the coarse fibers in the fibrous prefilter is about $45 \mu \mathrm{m}$. The actual aerosol collection filter is barely visible beneath the fibrous prefilter.

Figure 31 Higher magnification scanning electron photomicrograph of the aerosol collection side of the "fiber-front" Lepestok face mask. (Magnification is 370X. Scale factor is 2.7 $\mu \mathrm{m} / \mathrm{mm}$. The width of the visible image is $0.45 \mathrm{~mm}$.) The fiber diameter of the prefilter is approximately an order of magnitude greater than the fiber diameter of the aerosol collection filter.

Figure 32 Scanning electron photomicrograph of the fibrous prefilter (with the underlying aerosol collection filter removed) from a "fiber-front" Lepestok facemask. (Magnification is $370 \mathrm{X}$. Scale factor is $2.7 \mu \mathrm{m} / \mathrm{mm}$. The width of the visible image is $0.45 \mathrm{~mm}$.) The fibrous prefilter does not contribute to aerosol collection.

Figure 33 Scanning electron photomicrograph of the aerosol collection filter (with the fibrous prefilter removed) on the front side of the "fiber-front" Lepestok facemask. (Magnification is $370 \mathrm{X}$. Scale factor is $2.7 \mu \mathrm{m} / \mathrm{mm}$. Width of the visible image is $0.45 \mathrm{~mm}$.) The collection filter has a similar morphology to the filter material in the AFA-RMP-20 analytical filters and in the "gauze-front" Lepestok face masks.

Figure 34 Scanning electron photomicrograph of the gauze support on the back or face-side of the "fiber-front" Lepestok face mask. (Magnification is 370X. Scale factor is $2.7 \mu \mathrm{m} / \mathrm{mm}$. The width of the visible image is $0.45 \mathrm{~mm}$.) The face side of the "fiber-front" Lepestok facemask is similar to the face side of the "gauze-front" Lepestok facemask.

Figure 35 Higher magnification scanning electron photomicrograph of the gauze support mesh and the aerosol collection filter on the back or face-side of the "fiber-front" Lepestok face mask. (Magnification is 370X. Scale factor is $2.7 \mu \mathrm{m} / \mathrm{mm}$. The width of the visible image is $0.45 \mathrm{~mm}$.)

Figure 36Comparison of the alpha energy spectrum from ambient radon progeny collected in an Eberline Alpha-6 alpha continuous air monitor with a 1-inch diameter detector and a 1-inch diameter collection area for (red, the sharper peaked spectrum) a Millipore Fluoropore 5- $\mu \mathrm{m}$ pore size Teflon membrane filter (an excellent front surface collecting filter) and for (blue, the much broader spectrum) an AFA-RMP-20 analytical filter. The fibrous nature of the AFA-RMP-20 filter provides a "depth filter" rather than the "front-surface collecting filter". The alpha energy spectrum of the AFA-RMP-20 is similar to that of other glass fiber filters, such as the Whatman EPM-2000. 
Figure 37Alpha energy spectrum for ambient radon progeny collected on the back surface (with the gauze mesh support) of an AFA-RMP-20 analytical filter. The presence of the gauze mesh on the backside of the filter makes the alpha energy spectrum somewhat broader that the spectrum from the collection filter alone.

Figure $38^{\circ}$ Alpha energy spectrum for ambient radon progeny collected on the front surface of the "gauze-front" Lepestok facemask. The shape of the alpha energy spectrum is similar to that achieved on the back surface (with the gauze mesh support) of an AFA-RMP-20 analytical filter.

Figure 39 Alpha energy spectrum for ambient radon progeny collected on the front surface of a "fiber-front" Lepestok facemask. The presence of the fibrous prefilter makes the energy spectrum much broader than was achieved with the "gauze-front" Lepestok face mask and with the back surface (with the gauze mesh support) or the front surface of an AFA-RMP20 analytical filter. The broadening of the energy spectrum is due to the attenuation of the alpha energy as the alpha particle travels from the surface of the filter past (and partially through) the prefilter material.

Figure 40 Schematic diagram of the aerosol generation and collection system used for the filter efficiency study.

Figure 41 Photograph of the aerosol generation and collection system used for the filter efficiency study. The Lovelace nebulizer is on the left, the aerosol mixing and buffer chamber is in the center, the chamber pressure sensor is located above, and the test filter holders are located on the right.

Figure 42 Schematic drawing of the special filter holder assembly used to determine the penetration of $0.3-\mu \mathrm{m}$ aerodynamic diameter monodisperse fluorescent particles through 47-mm diameter samples of filter media.

Figure 43 Photograph of the filter holder assembly for measuring penetration through filter media. From upper left to upper right, the components are the filter holder exhaust section, a stainless steel perforated-plate support screen, a high efficiency backup filter (a Millipore Fluoropore 5- $\mu \mathrm{m}$ pore Teflon membrane filter), an o-ring, a second support screen, the filter to be tested, a second o-ring (not shown), the inlet barrel, the retaining ring which screws onto the exhaust section, and an inlet adapter to connect the holder assembly to the aerosol chamber. 


\section{INDEPENDENT EVALUATION OF AIR FILTER MEDIA}

\section{FROM CHORNOBYL}

\section{INTRODUCTION}

An independent evaluation was performed to assess the morphology, pressure drop characteristics, alpha spectroscopy characteristics, and collection efficiency of an air sampling filter media and two types of aerosol face masks provided from Chornobyl by Pacific Northwest National Laboratory. The evaluation included characterizing the filter morphology by scanning electron microscopy; measuring the filter pressure drop as a function of air flowrate; evaluating the spectroscopy characteristics of the filter for alpha-emitting radionuclides by sampling ambient radon progeny aerosols in an Eberline Alpha-6A alpha continuous air monitor; determining the particle collection efficiency of the filter media for $0.3 \mu \mathrm{m}$ aerodynamic diameter monodisperse particles at 1 and $2 \mathrm{cfm}$; and comparing the apparent construction, durability, and performance similarities of the filter media to other media commonly used for monitoring airborne alpha-emitting radionuclides.

\section{FILTER TYPES}

Samples of three types of air filters were obtained by the PNNL project officer and provided to LRRI for evaluation:

1. AFA-RMP-20 analytical aerosol filters (in two identical cardboard cartons, referred to in this report as the A and B samples);

2. Lepestok personal face masks with a gauze front surface (referred to in this report as the "gauze-front" facemasks); and

3. Lepestok personal face masks with a smoother fiber-type front surface (referred to in this report as the "fiber-front" facemasks). 


\section{FILTER MORPHOLOGY}

Digital photographs and scanning electron photomicrographs were taken for the A and B samples of the AFA-RMP-20 filters, for the gauze-front Lepestok face masks, and for the fiberfront Lepestok face masks. (See Figures 1-35.)

\section{AFA-RMP-20 Filters}

Appendix A contains an English translation of the Russian language text of the manufacturer's "DATA CERTIFICATE for AFA-RSP analytical filters" which came with each cardboard carton of the AFA-RMP-20 filters. The certificate states that the filters conform to industry standard OST 95.10052-84. Each cardboard carton of the AFA-RMP-20 filters contains 10 packets of 10 filters each, for a total of 100 filters in each carton.

The essentially identical construction and quality of the A and B samples of the AFARMP-20 filters is consistent with the fact that they came from identical cartons with the same manufacturing label information. The collection surface appears to be a cotton or paper fiber mesh. There is a woven cotton gauze support on the backside of the filters. The gauze has about 38 threads per $5 \mathrm{~cm}$ (nominally 20 threads per inch) in one direction and about 59 threads per $5 \mathrm{~cm}$ (nominally 30 threads per inch) in the other direction.

\section{Gauze-Front Lepestok Mask}

A similar woven gauze support material is found on the front and back surfaces of the gauze-front mask. These front and back layers don't contribute to the collection performance of the filter, but provide some physical stability and protection to the main fiber filter. The fiber filter in between the gauze layers has the appearance of a typical glass fiber filter and, as such, its surface is somewhat easy to disrupt by rubbing.

\section{Fiber-Front Lepestok Mask}

The fiber-front mask has a similar woven gauze support on the back surface, and a relatively smooth, white, fiber filter on the collection side. 


\section{FILTER PRESSURE DROP PERFORMANCE}

A convenient measure of the pressure drop performance of a filter is $\mathrm{L} / \mathrm{min} / \mathrm{cm}^{2}$ at $5 \mathrm{psi}$. Once measured, this value can be scaled in a linear fashion on the basis of available surface area to determine the pressure drop as a function of flowrate or the flowrate as a function of pressure drop. Appendix B of this report lists the pressure drop relationships for a number of commonly used filters as reported in Appendix D of ANSI N13.1 1999 (Glissmeyer et al. 1999). For a membrane filter like the Millipore AW-19 filter the value is about 16, for a coarse cotton fiber filter like the Whatman 41 the value is 25 , for a fine glass fiber filter like the Gelman $A / E$ glass the value is also 25 , and for a very low pressure Teflon membrane filter like the Millipore fluoropore $5 \mu \mathrm{m}$ pore filter the value is about 60 . The pressure drops for the filter media evaluated in this report are quite low, which is to be expected for coarse-fiber media. The value for the Filter A and B media is about $60 \mathrm{~L} / \mathrm{min} / \mathrm{cm}^{2}$, and the values for the gauze-front and the fiber-front masks are each about $73 \mathrm{~L} / \mathrm{min} / \mathrm{cm}^{2}$.

\section{ALPHA SPECTROSCOPY CHARACTERISTICS}

The resolution of alpha energy spectra observed with an Eberline Alpha- 6 continuous air monitor is relatively coarse for radon progeny collected on samples of the AFA-RMP-20 filters, gauze-front face masks, and fiber-front face masks. Spectra are typical of coarse fiber-type filter media (Hoover and Newton 1993), and are shown in Figures 36-43. The AFA-RMP-20 and Lepestok face mask filter media would not provide good alpha spectra for continuous air monitoring, but would be suitable for other sampling applications that only require collection of the aerosol of interest.

\section{PARTICLE COLLECTION EFFICIENCY}

The collection efficiency for $0.3-\mu \mathrm{m}$ aerodynamic diameter particles was determined for all four filter media at a flowrate of $28.3 \mathrm{~L} / \mathrm{min}$ using $47-\mathrm{mm}$ diameter filter samples, with a $42-$ $\mathrm{mm}$ diameter for the collection area. A description of the penetration test assembly is given in Figures 37 - 40. Based on four tests for each material, the collection efficiency of the Filter A media was $97.9 \% \pm 0.6 \%$. As expected, the collection efficiency of the Filter $B$ media was similar at $97.4 \% \pm 0.8 \%$. The combined efficiency for the Filter $A$ and $B$ media was $97.7 \% \pm$ 
$0.7 \%$. Because collection efficiency is lowest for $0.3 \mu \mathrm{m}$ diameter particles, and will be higher for smaller particles due to diffusion and larger particles due to inertial impaction, the performance of this filter media is good (greater than 95\%) but not excellent (greater than 99.97\%).

The particle collection efficiency for the "gauze-front" facemask was $93.8 \% \pm 0.5 \%$, and the collection efficiency for the "fiber-front" facemask was $95.1 \% \pm 0.7 \%$. Although the two results are not statistically different, the presence of the finer surface of the "fiber-front" mask may contribute to the slightly better performance of the "fiber-front" mask. The collection efficiency of the surface layer of the "fiber-front" mask was measured for two samples of this material and found to be $79.7 \%$ and $82.5 \%$ (i.e., about $81 \% \pm 2 \%$ ). Note that a series calculation for two filter media with individual efficiencies of $81 \%$ and $94 \%$ would give a combined efficiency of more than $98 \%$. Because the measured efficiency of the filter pair was less than the calculated series efficiency, it is likely that the physical position of the prefilter on top of the main filter results in a smaller effective efficiency for the combined filters (i.e., the two filters do not behave independently when they are placed in direct contact with each other). (Note that the series calculation is based on the penetration values, where penetration is 0.19 through the first filter times 0.06 through the second filter, yielding 0.011 penetration overall, which corresponds to 0.989 calculated retention for the filter series.)

Data for the pressure drop performance and collection efficiency measurements for the Chornobyl filter media are summarized in Table 1. Note that the slightly higher collection efficiency for the AFA-RPM-20 filter is associated with a greater resistance to airflow.

\section{Table 1: Summary of Pressure Drop Performance and Collection Efficiency Measurements for the Chornobyl Filter Media}

\begin{tabular}{|c|c|c|}
\hline Filter Media & $\begin{array}{c}\text { Pressure Drop } \\
\text { Factor } \\
\left(\mathrm{L} / \mathbf{m i n}_{\mathbf{c}} \mathbf{c m}^{\mathbf{2}}\right)\end{array}$ & $\begin{array}{c}\text { Collection Efficiency } \\
\text { For 0.3- } \mu \text { m Aerodynamic } \\
\text { Diameter Particles }\end{array}$ \\
\hline $\begin{array}{c}\text { AFA-RMP-20 } \\
\begin{array}{c}\text { Gauze-Front Lepestok } \\
\text { Facemask }\end{array}\end{array}$ & 60 & $97.7 \% \pm 0.7 \%$. \\
\hline $\begin{array}{c}\text { Fiber-Front Lepestok } \\
\text { Facemask }\end{array}$ & 73 & $93.8 \% \pm 0.5 \%$ \\
\hline
\end{tabular}




\section{SIMILARITIES TO OTHER FILTER MEDIA}

Appendix B (excerpted from ANSI N13.1 1999) lists the collection efficiencies of a number of common filters for air sampling of plutonium and other airborne radionuclides. The AFA-RMP-20 and the "fiber-front" and "gauze-front" Lepestok filter media are somewhat better in performance than the Gelman $\mathrm{A} / \mathrm{E}$ glass filter, which has a nominal pore size of $1 \mu \mathrm{m}$, a pressure drop of about $25 \mathrm{~L} / \mathrm{min} / \mathrm{cm}^{2}$ at 5 psig, a collection efficiency of $0.3 \mu \mathrm{m}$ particles of about $92 \% \pm 1 \%$, and a poor spectroscopy resolution. Their pressure drop is about half as great, and their efficiency is slightly higher. The performance of these media is better than that of the Whatman 41 , which has a notoriously low collection efficiency of only $42 \%$ for $0.3 \mu \mathrm{m}$ diameter particles. There performance is generally similar to the performance of the Whatman EPM-2000 microglass fiber filter, which is adequate for applications that do not require alpha spectroscopy and do not require collection efficiencies higher than $99 \%$.

\section{ACKNOWLEDGMENTS}

This work was performed at the Lovelace Respiratory Research Institute under funding from the Pacific Northwest National Laboratory International Nuclear Safety Program. Collaboration of the Chornobyl scientists is gratefully acknowledged. Research at LRRI for the U.S. Department of Energy is performed under U.S. Department of Energy Cooperative Agreement No. DE-FC04-96AL76406.

\section{REFERENCES}

Data Certificate for AFA-RSP Analytical Filters, Manufacturers Documentation packaged with each carton of the AFA-RPM-20 Analytical Filter.

Glissmeyer, J. A., J. L. Alvarez, B. C Blunt, P. W. Frame, M. D. Hoover, A. P. Hull, J. M. Karhnak, A. R. McFarland, G. J. Newton, and J. C. Rodgers: Sampling and Monitoring Releases of Airborne Radioactive Substances from the Stacks and Ducts of Nuclear Facilities, ANSI/HPS N13.1-1999, Health Physics Society, McLean, VA, 1999.

Hoover, M. D. and G. J. Newton: Radioactive Aerosols. In Aerosol Measurement: Principles, Techniques, and Applications, (K. Willeke and P. A. Baron, eds.), pp. 768-798, Van Nostrand Reinhold, New York, 1993. 


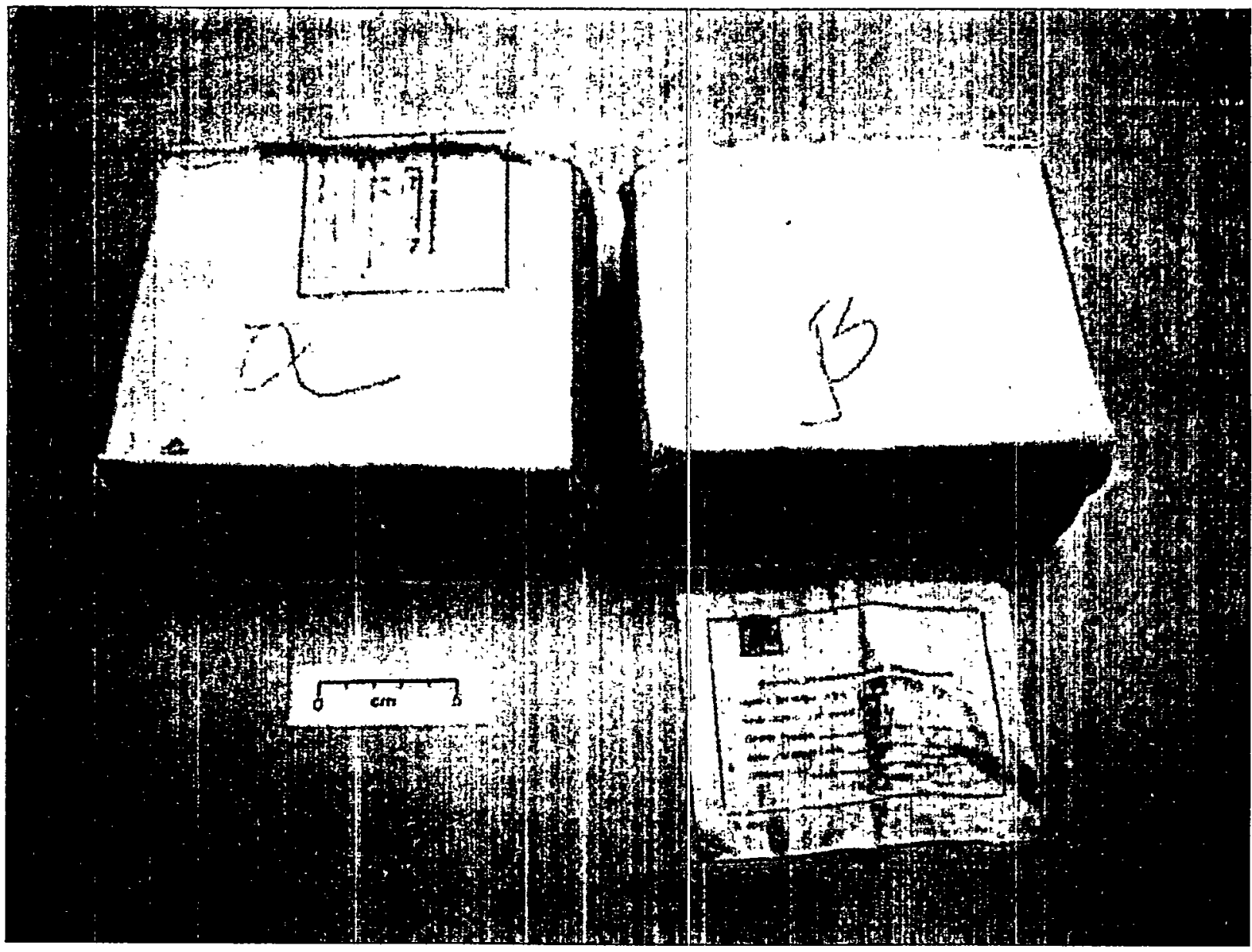

Figure 1 View of the two cartons of AFA-RMP-20 filters provided for testing. The manufacturer's labels are shown in the original position on the carton marked with the letter "alpha" and detached from the carton marked with the letter "beta". 


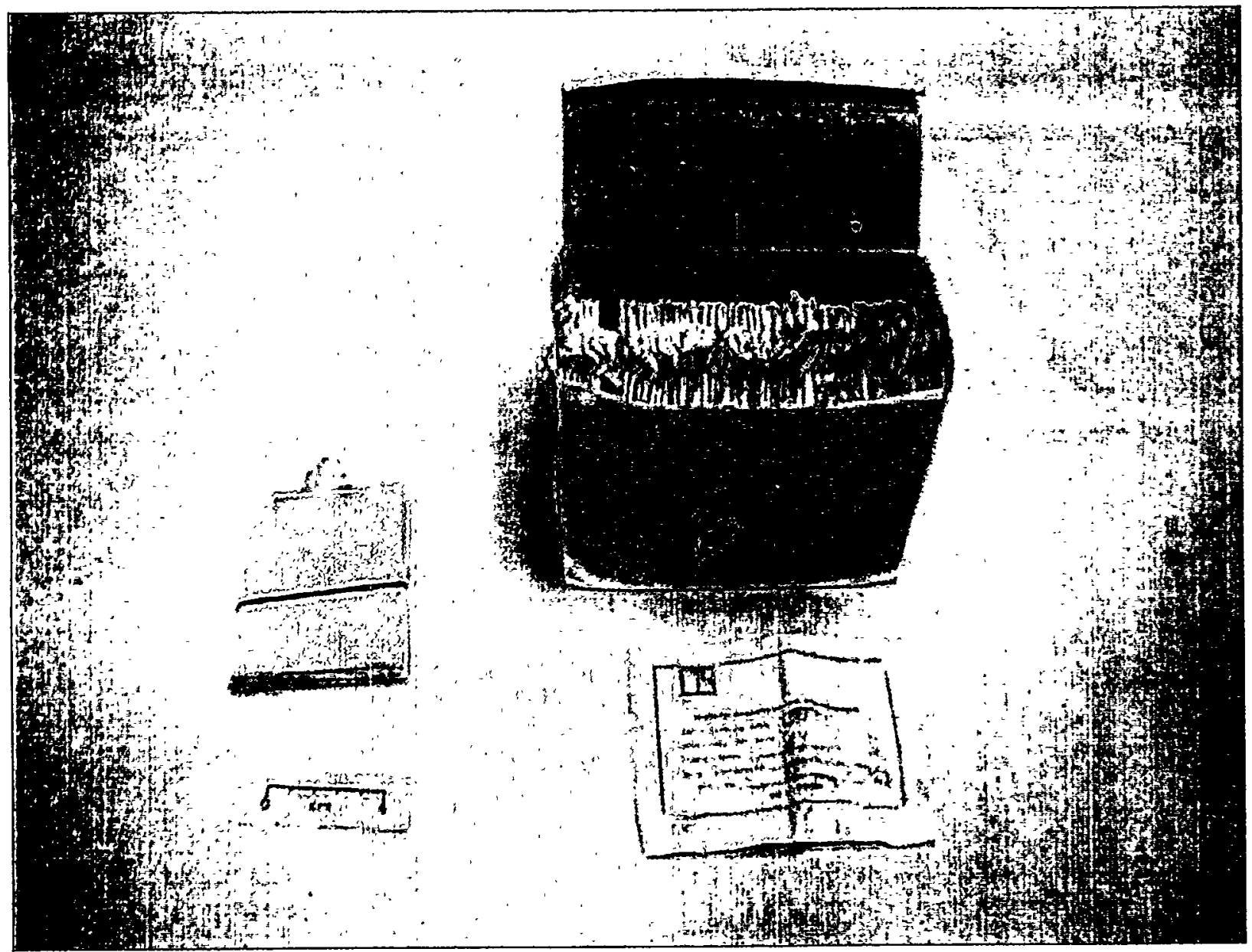

Figure 2 View of an open carton of AFA-RMP-20 filters, with an individual paper holder of filters removed from the carton. Each paper holder is secured with a rubber band and contains 10 filters. There are 10 holders per carton. 


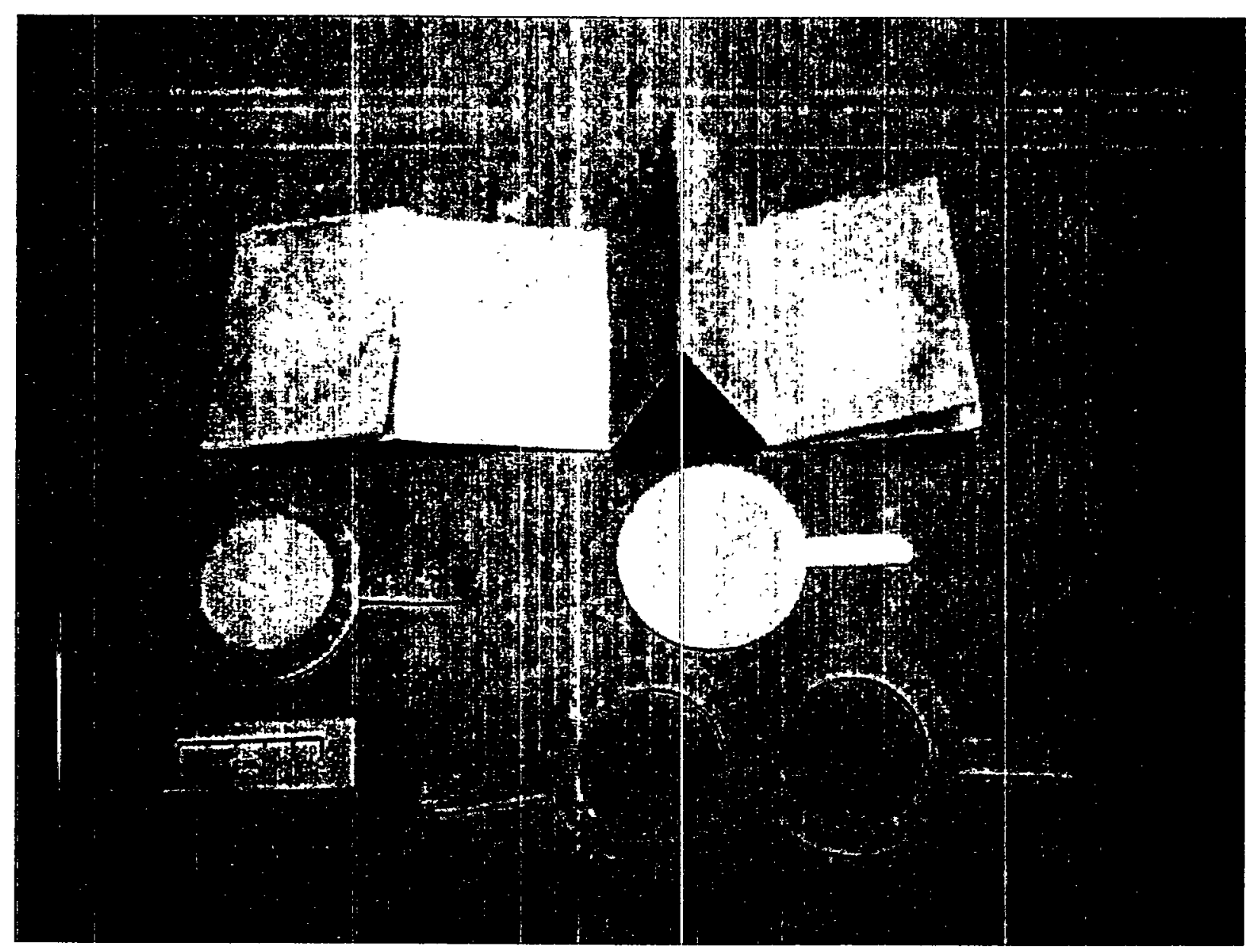

Figure 3 View of an open paper filter holder with two of the AFA-RMP-20 filters removed. Each filter consists of a filter element in the form of a disk. The backside of the filter element has a gauze support mesh. The collection side of the filter disk is glued to a white paper support ring with a projecting handle. Each filter has a removable, protective brown paper ring with a projecting handle. The filter on the left has the protective rings in place and the filter on the right has the protective rings removed. 


\section{AFA-RMP-20 ANALYTICAL FILTER}
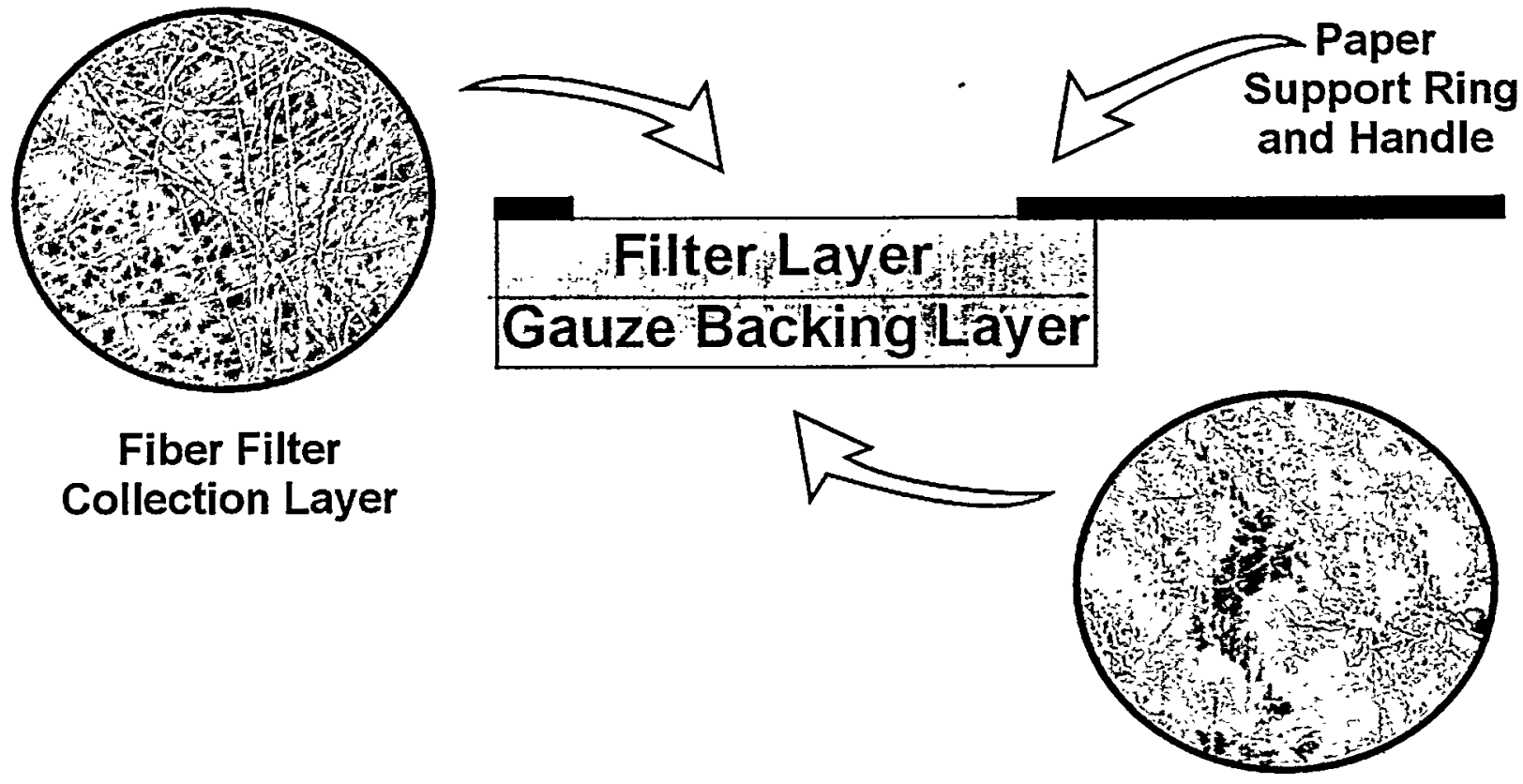

Gauze Backing Layer

40กิน-3

Figure 4 Schematic diagram of the AFA-RMP-20 filter assembly (not to scale) showing the relative positions of the paper support ring and handle, the fiber filter collection layer, and the gauze backing layer. The brown paper protective ring is not shown. 


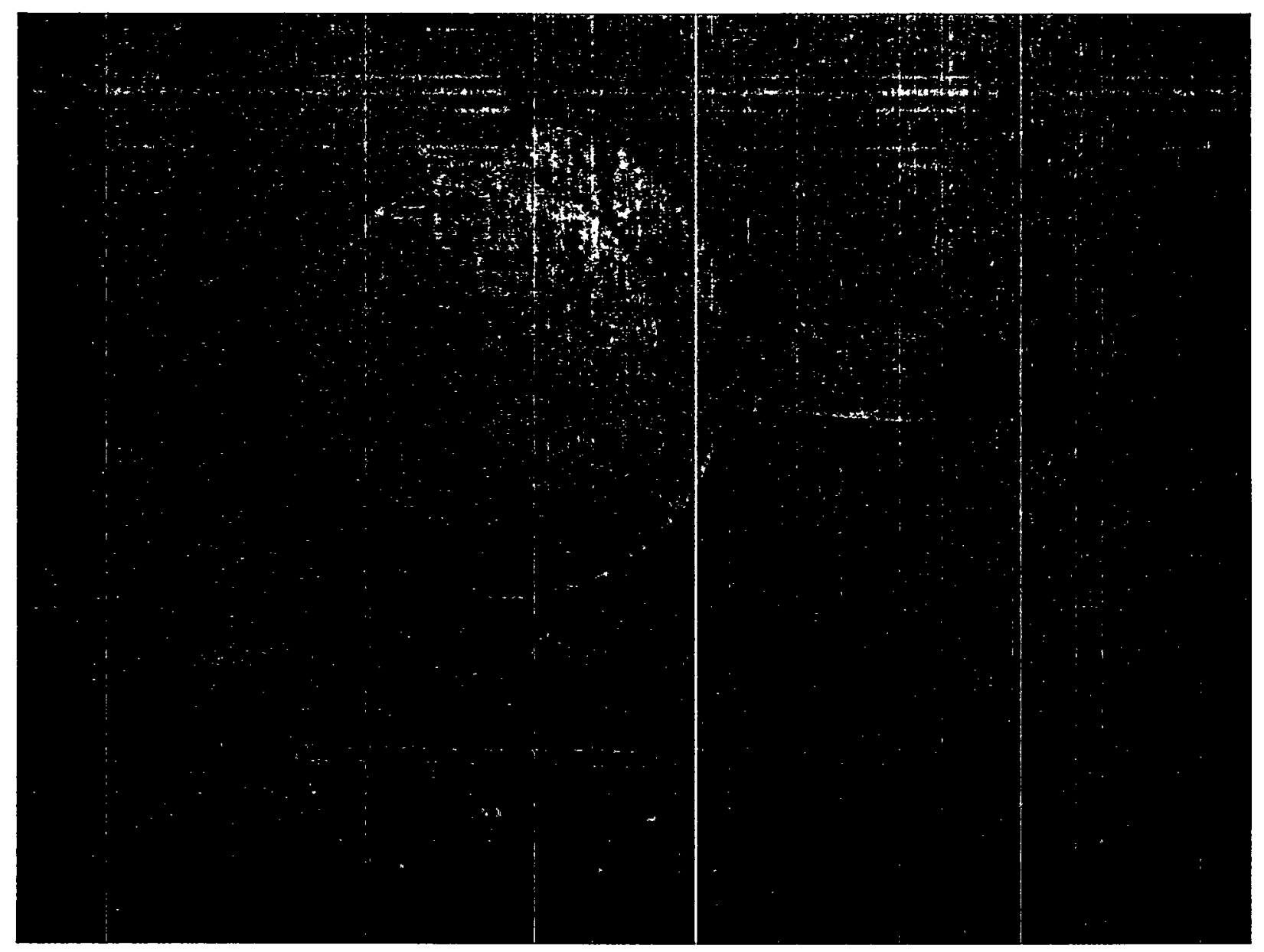

Figure 5 Closer view of an AFA-RMP-20 filter with its protective brown paper ring. 


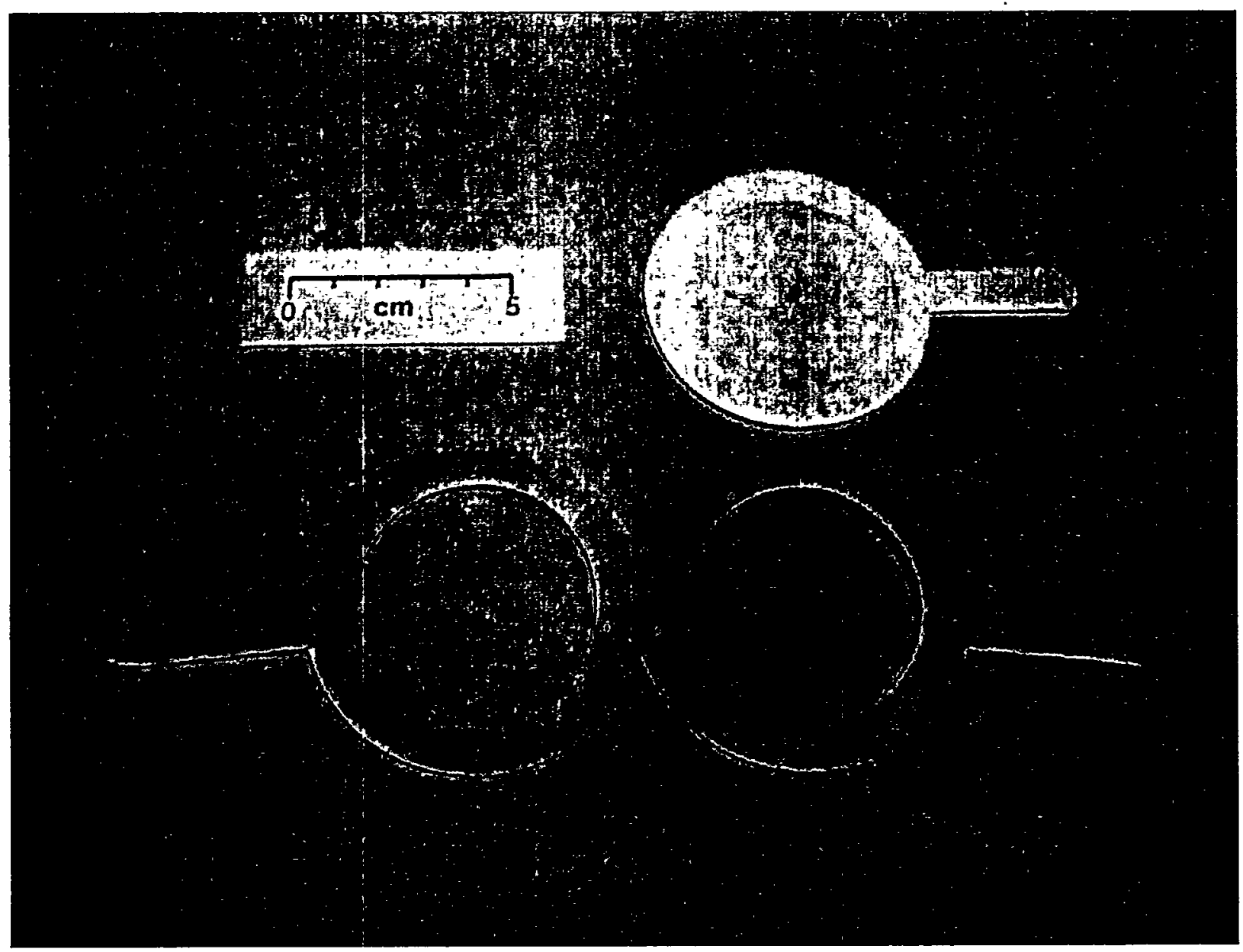

Figure 6 Closer view of an AFA-RMP-20 filter with its protective rings removed. The white paper support ring and handle can be seen glued on the top surface of the filter itself. 


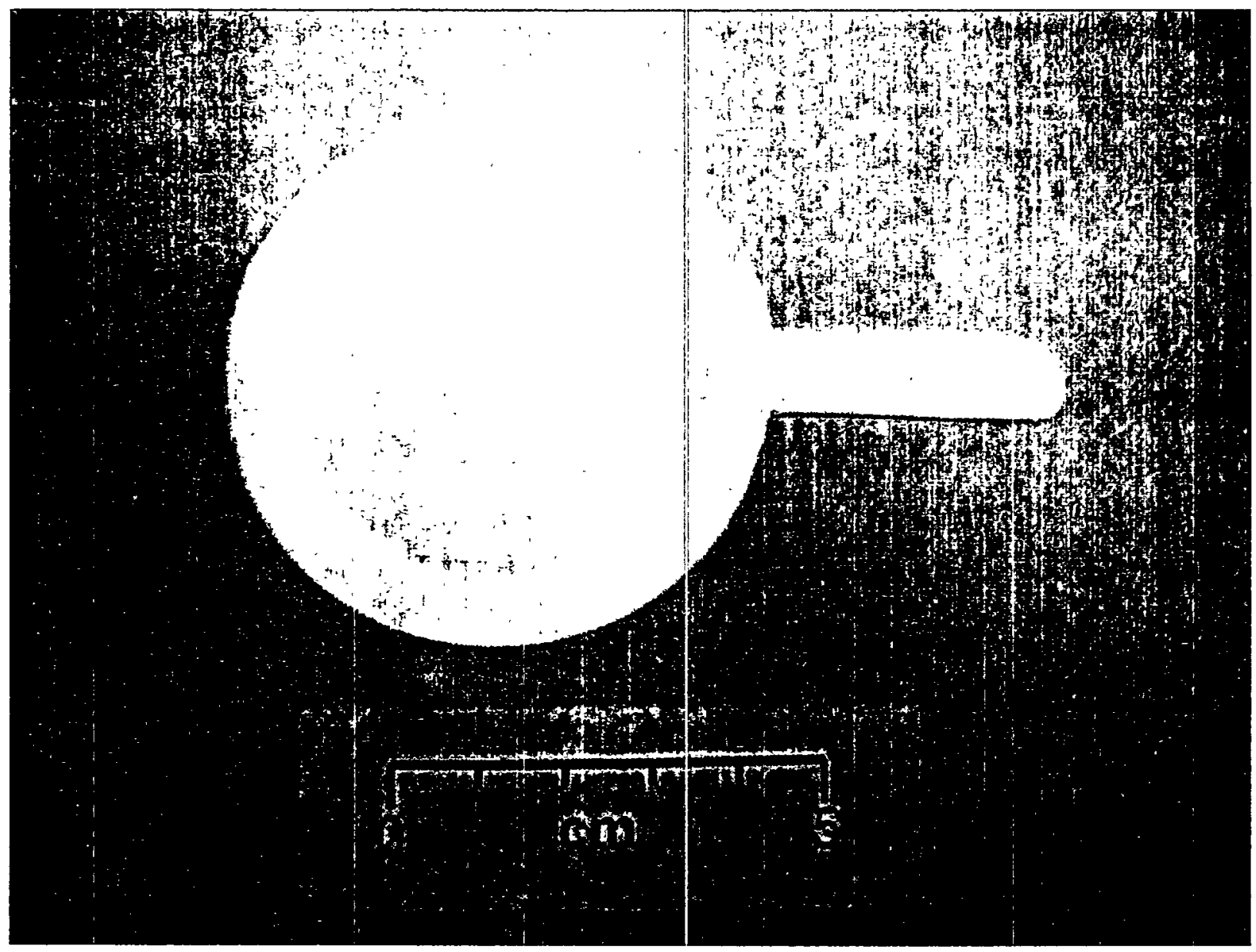

Figure 7 View of the collection side of an AFA-RMP-20 filter. The paper support ring with a projection for handling the filter is glued to the collection side of the filter. 


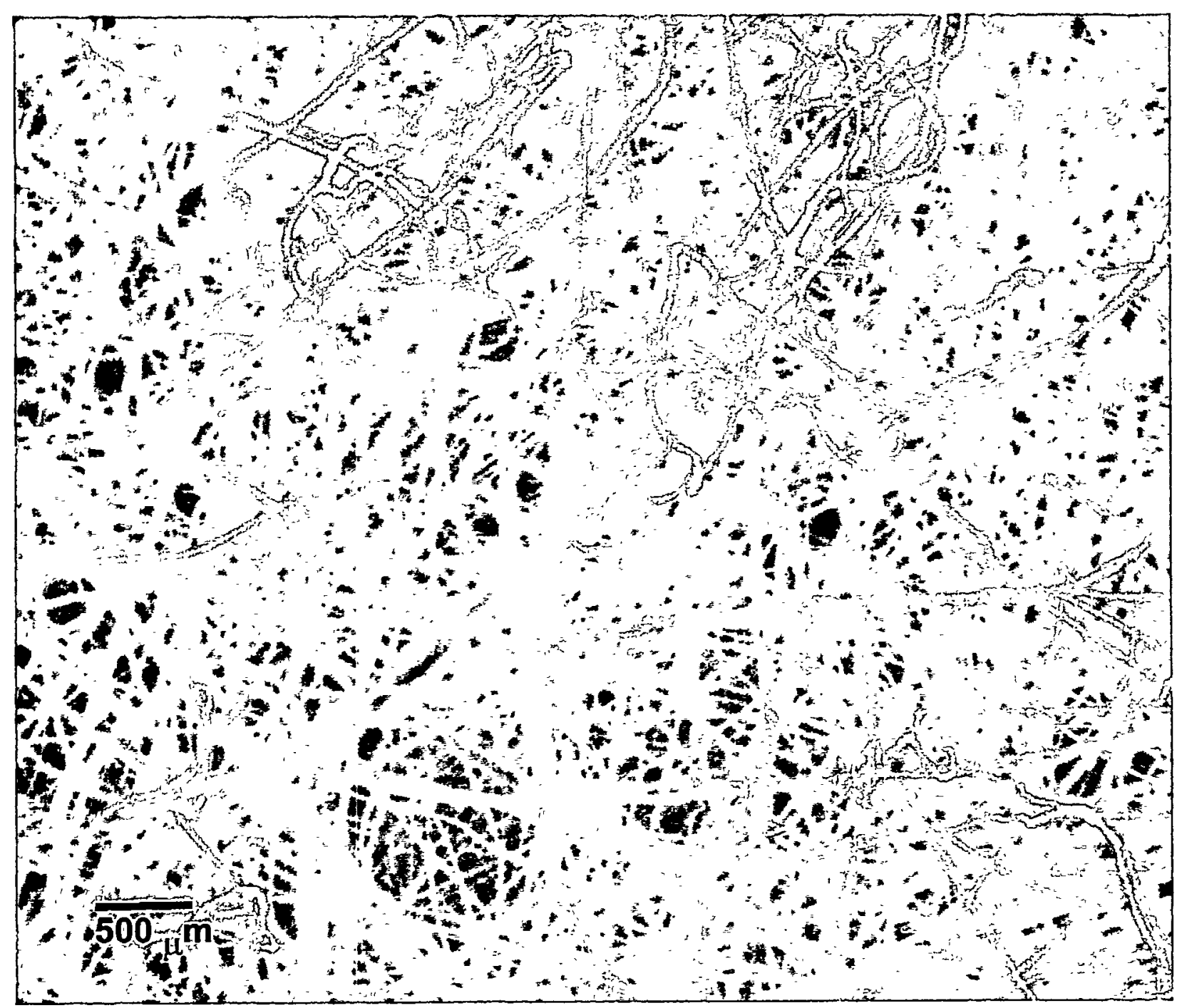

Figure 8 Scanning electron photomicrograph of the collection surface of an AFARMP-20 fiber-type analytical filter. (Magnification is 37X. Scale factor is $27 \mu \mathrm{m} / \mathrm{mm}$. The width of the visible image is $4.5 \mathrm{~mm}$.) The typical fiber diameters are on the order of $1 \mu \mathrm{m}$. Typical fiber lengths are on the order of millimeters. 


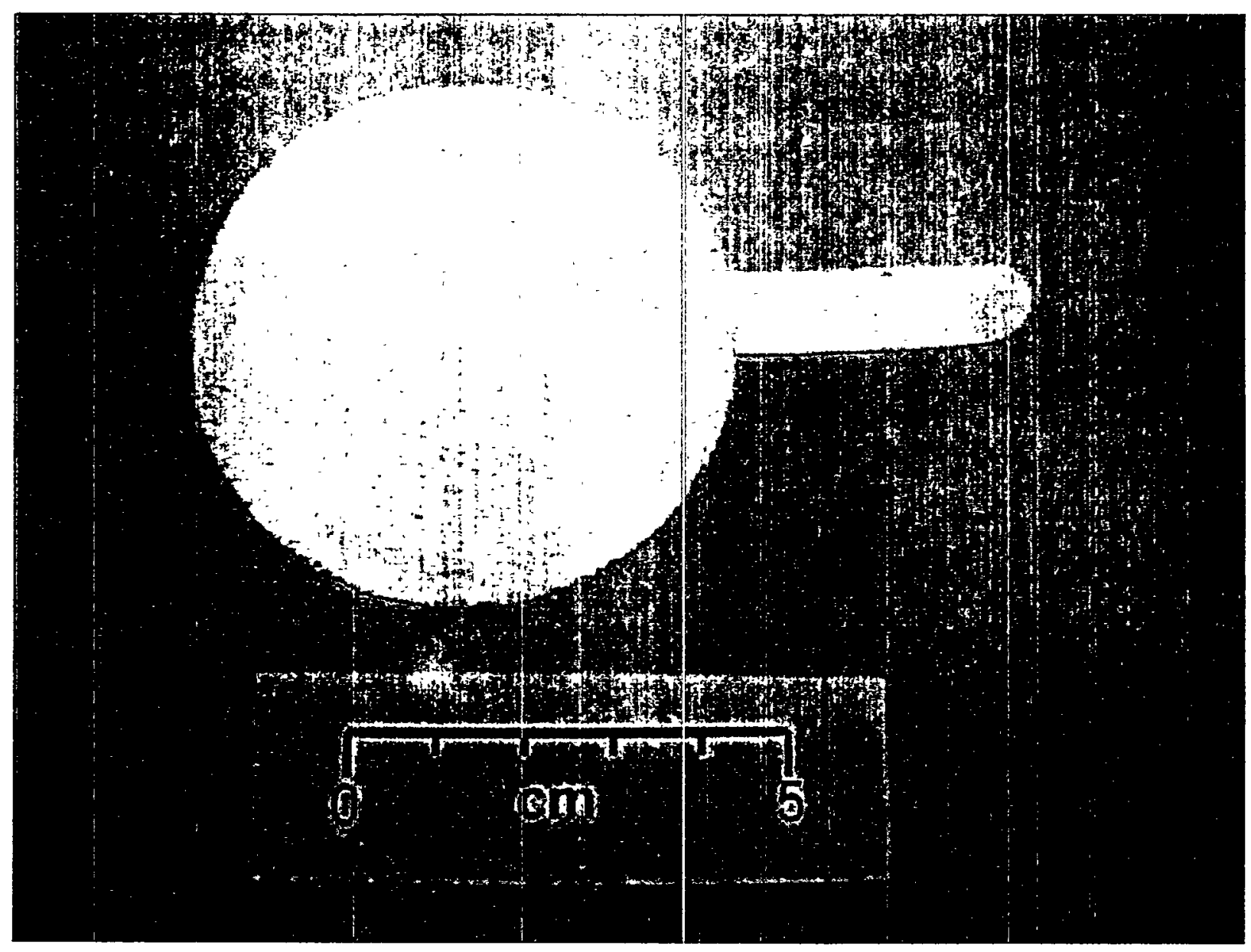

Figure 9 View of the gauze support mesh on the backside of an AFA-RMP-20 filter. 


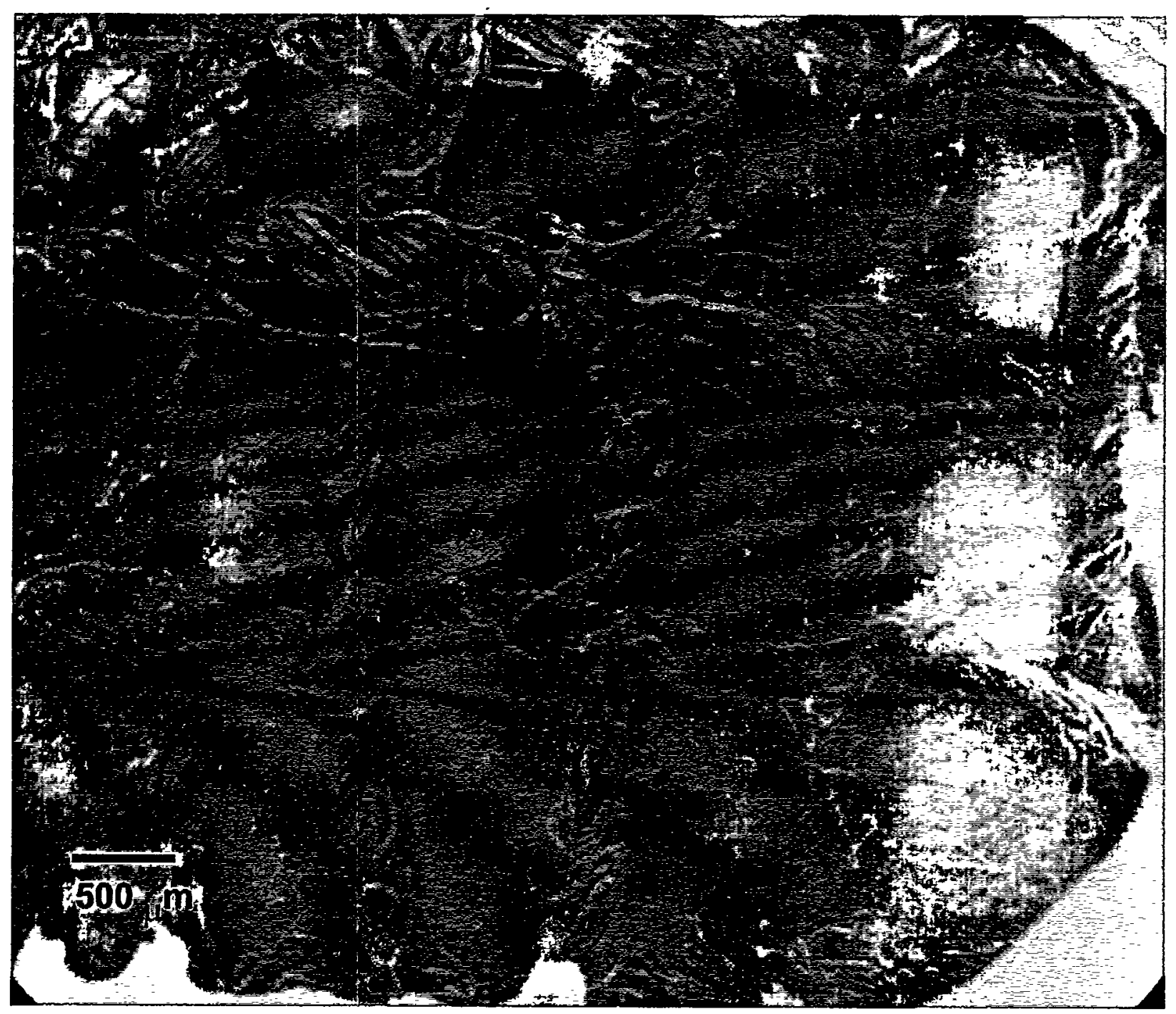

Figure 10 Scanning electron photomicrograph of the gauze support side (backside) of an AFA-RMP-20 fiber-type analytical filter. (Magnification is 37X. Scale factor is 27 $\mu \mathrm{m} / \mathrm{mm}$. The width of the visible image is $4.5 \mathrm{~mm}$.) The typical diameter of the thread bundles of the gauze is about $0.3 \mathrm{~mm}$. The typical diameter of the individual threads in the gauze fiber bundles is about $10 \mu \mathrm{m}$. 


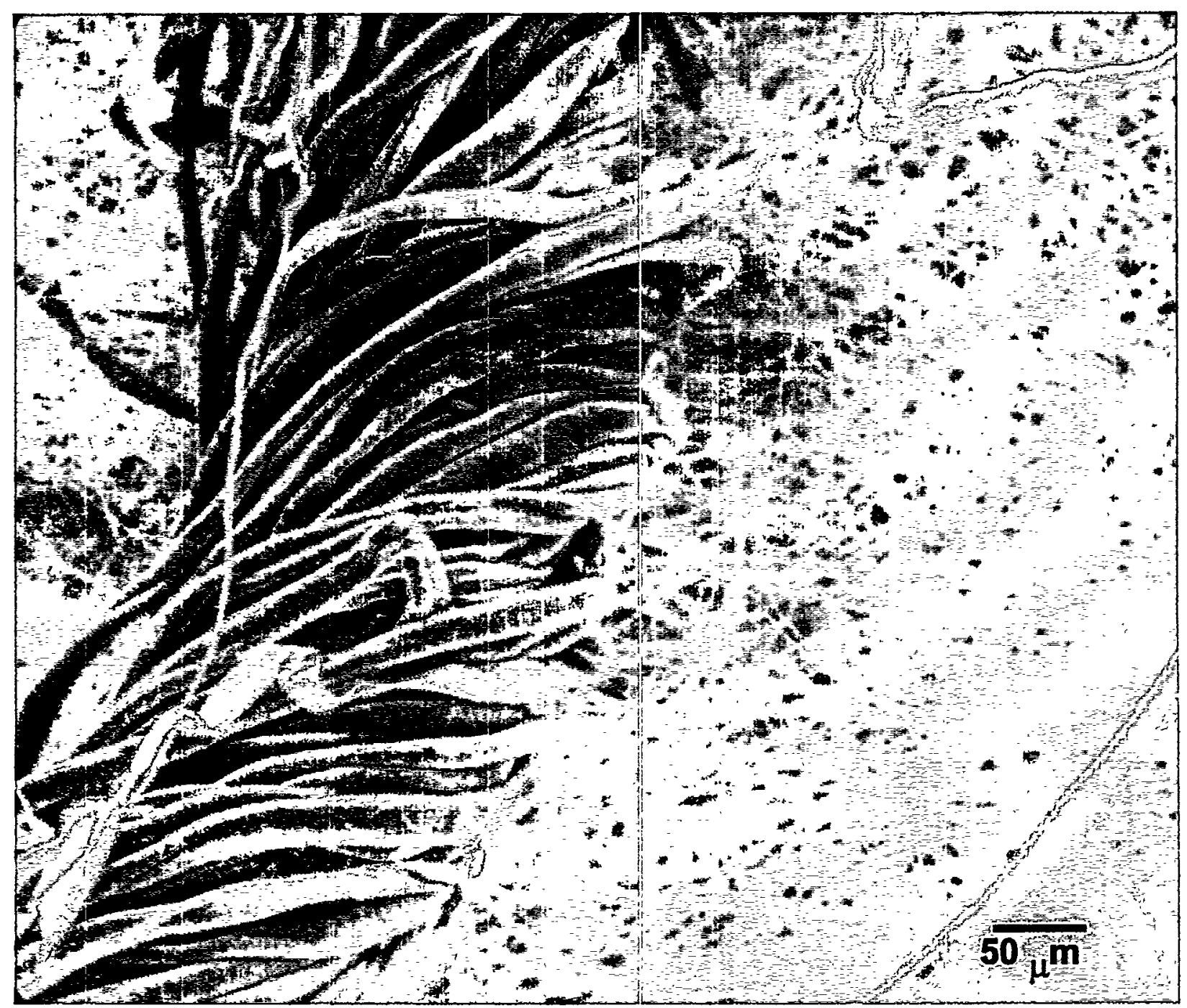

Figure 11 Higher magnification scanning electron photomicrograph of the gauze support side (back side) of an AFA-RMP-20 fiber-type analytical filter. (Magnification is 370X. Scale factor is $2.7 \mu \mathrm{m} / \mathrm{mm}$. The width of the visible image is $0.45 \mathrm{~mm}$.) The fiber matrix of the collection filter is more clearly visible in the background. 


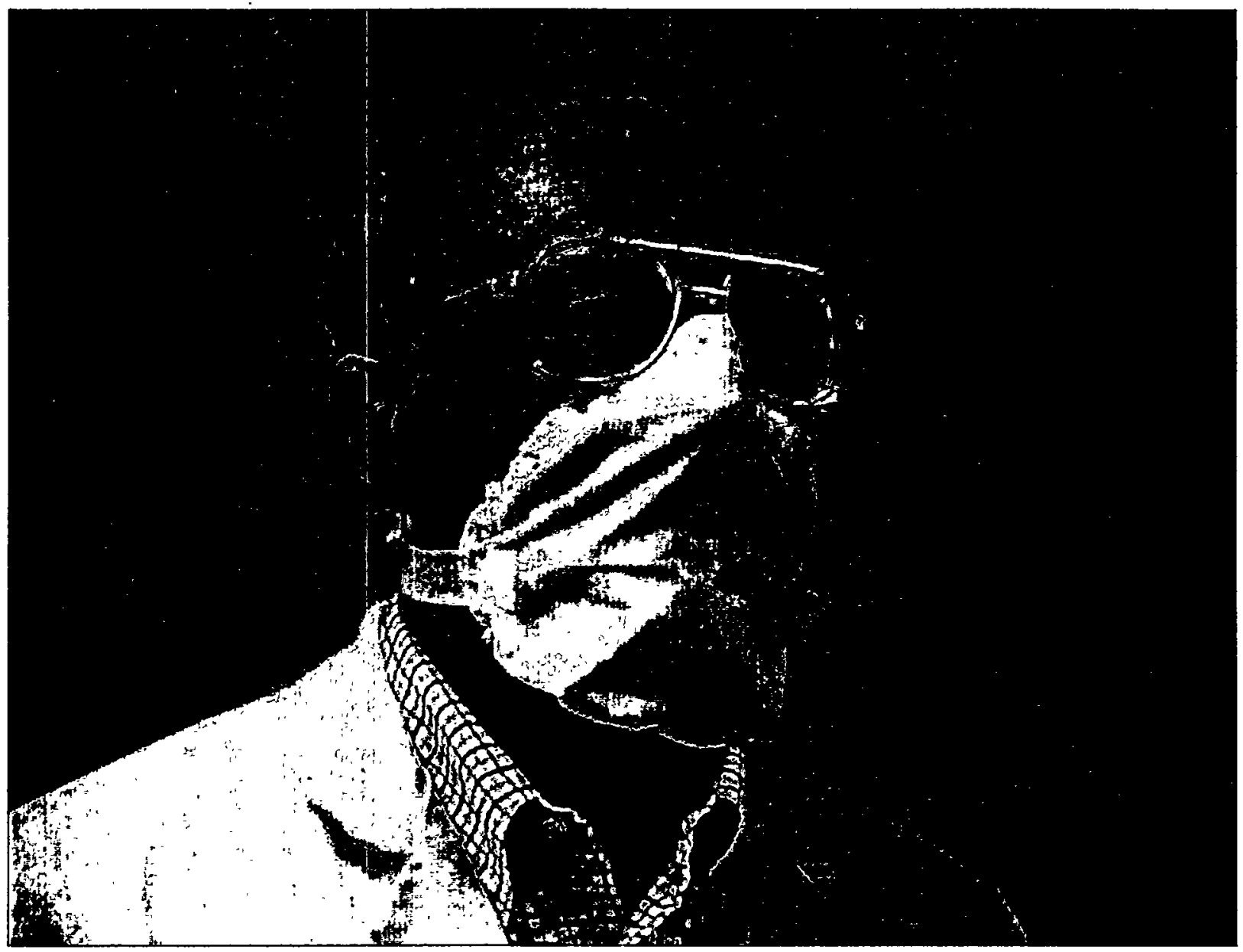

Figure 12 View of a "gauze-front" Lepestok facemask being worn by an adult male. A soft metal clip in the top edge of the mask holds the mask on the bridge of the nose. A pair of elastic cords in the bottom edge of the mask pull the mask into a bunched shape under the chin. Two cloth ties attached to the central edges of the mask are tied behind the neck to secure the mask on the face. A star-shaped plastic frame on the inside of the mask helps retain a proper shape of the mask over the mouth area. The "fiber-front" Lepestok face mask has a similar appearance when worn. 


\section{GAUZE-FRONT FACE MASK}

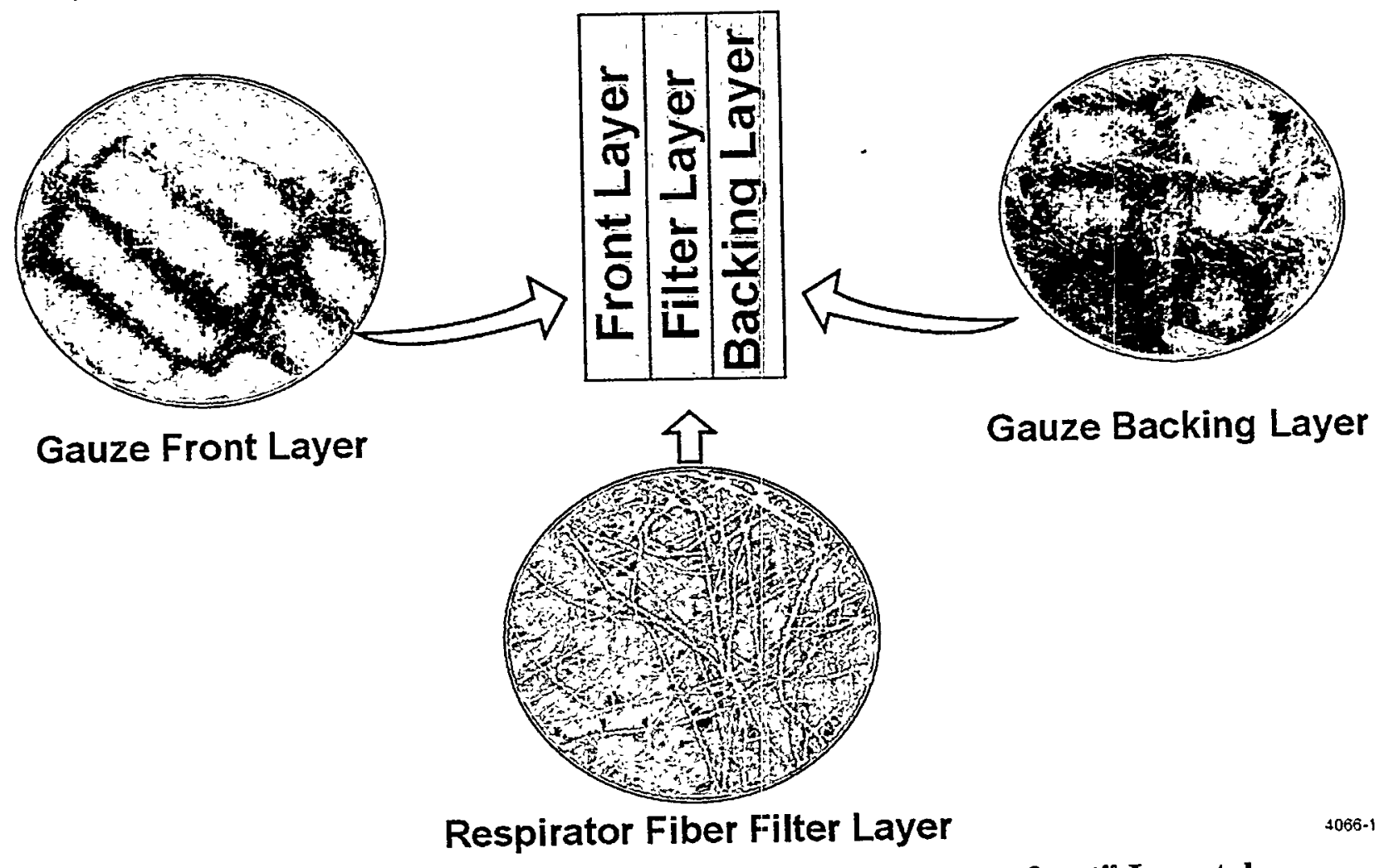

Figure 13 Schematic diagram of the construction of the "gauze-front" Lepestok facemask. The filter layer is supported on the front and back sides by gauze. The gauze layers and the filter layer are similar to the gauze and filter materials used in the AFARMP-20 fiber-type analytical filter. 


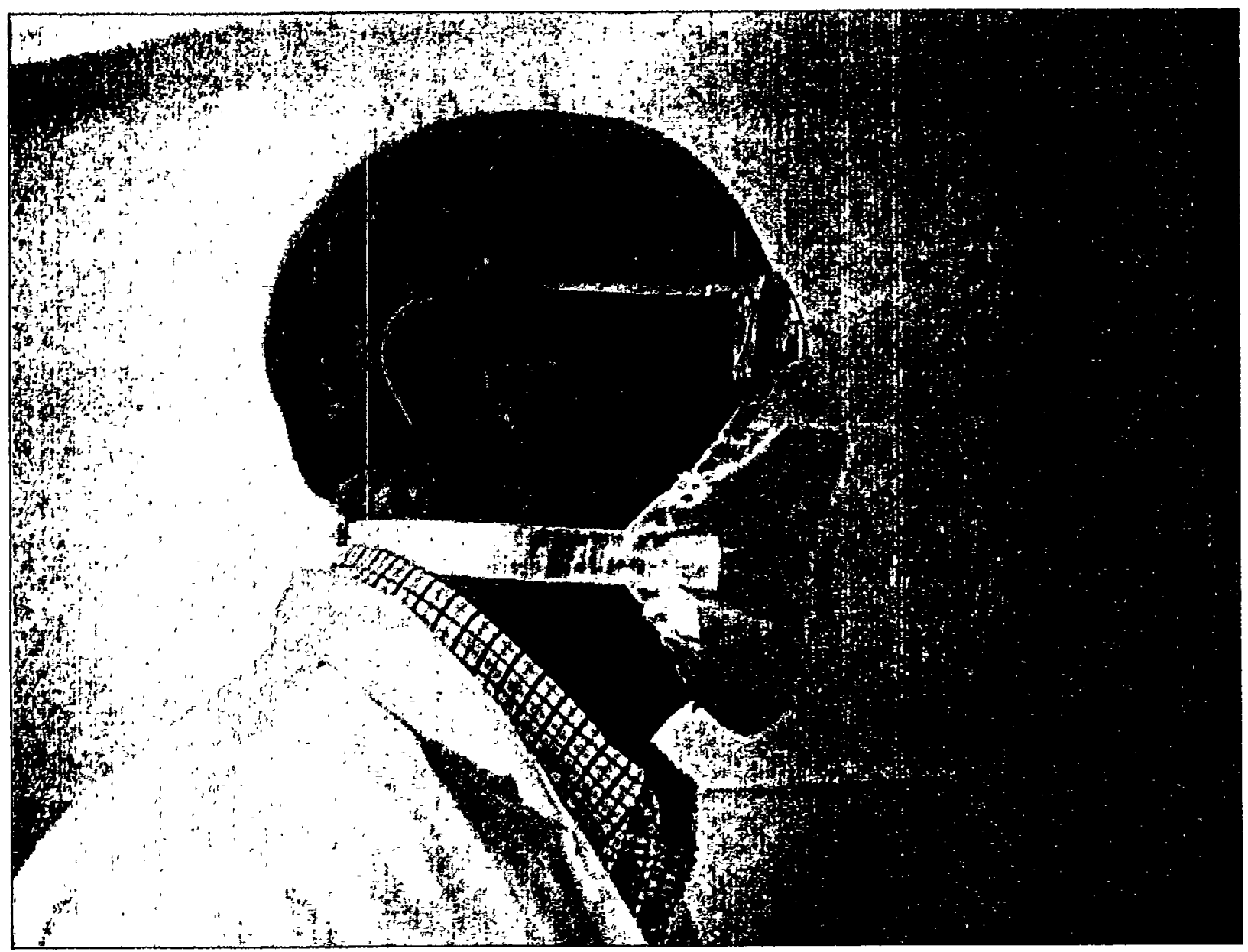

Figure 14 Side view of a Lepestok facemask being worn by an adult male. Note how the internal metal clip at the top of the mask positions the mask on the bridge of the nose and how the elastic cords on the bottom edges of the mask pull the mask into position under the chin. 


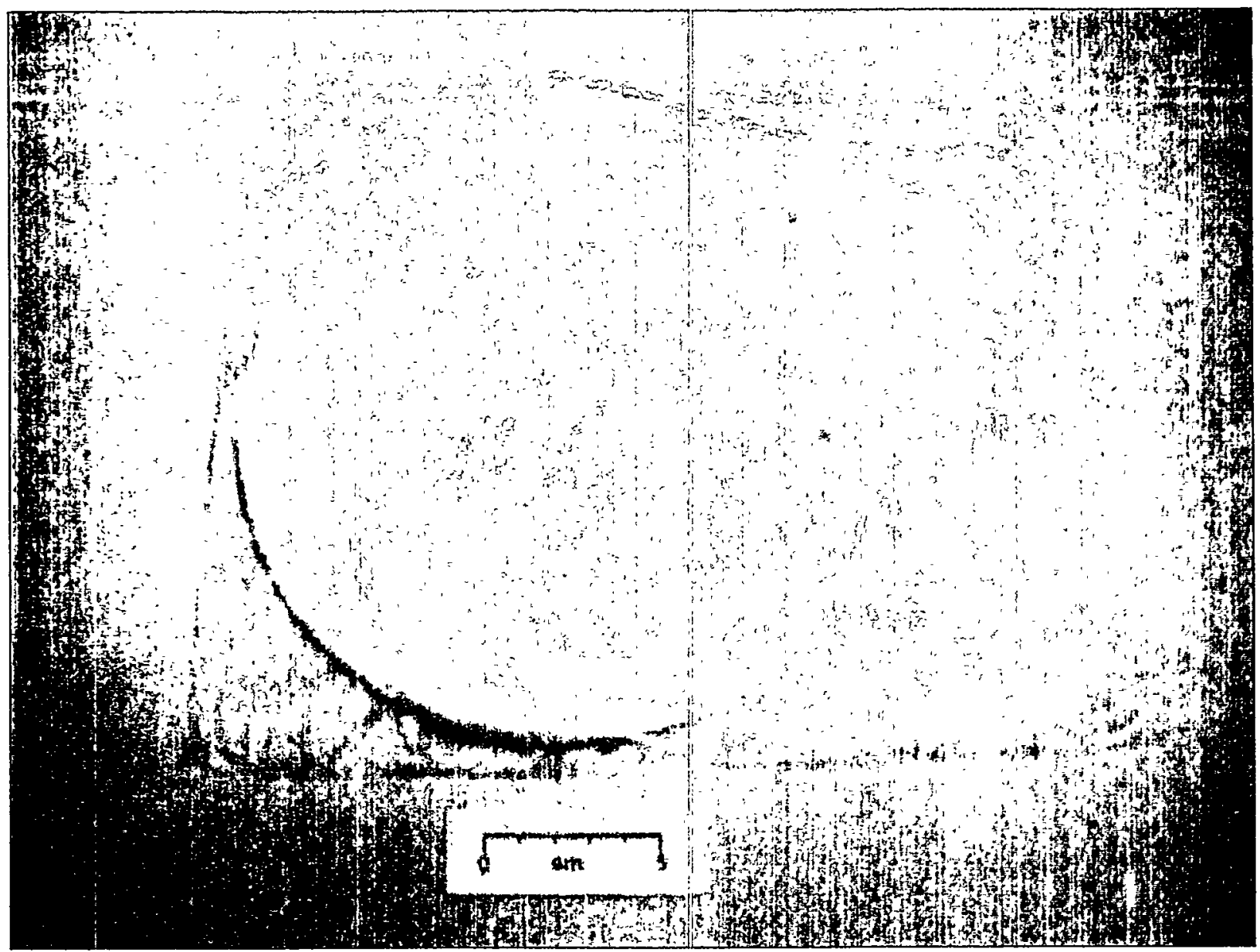

Figure 15 View of a package of the "gauze-front" Lepestok face masks. 


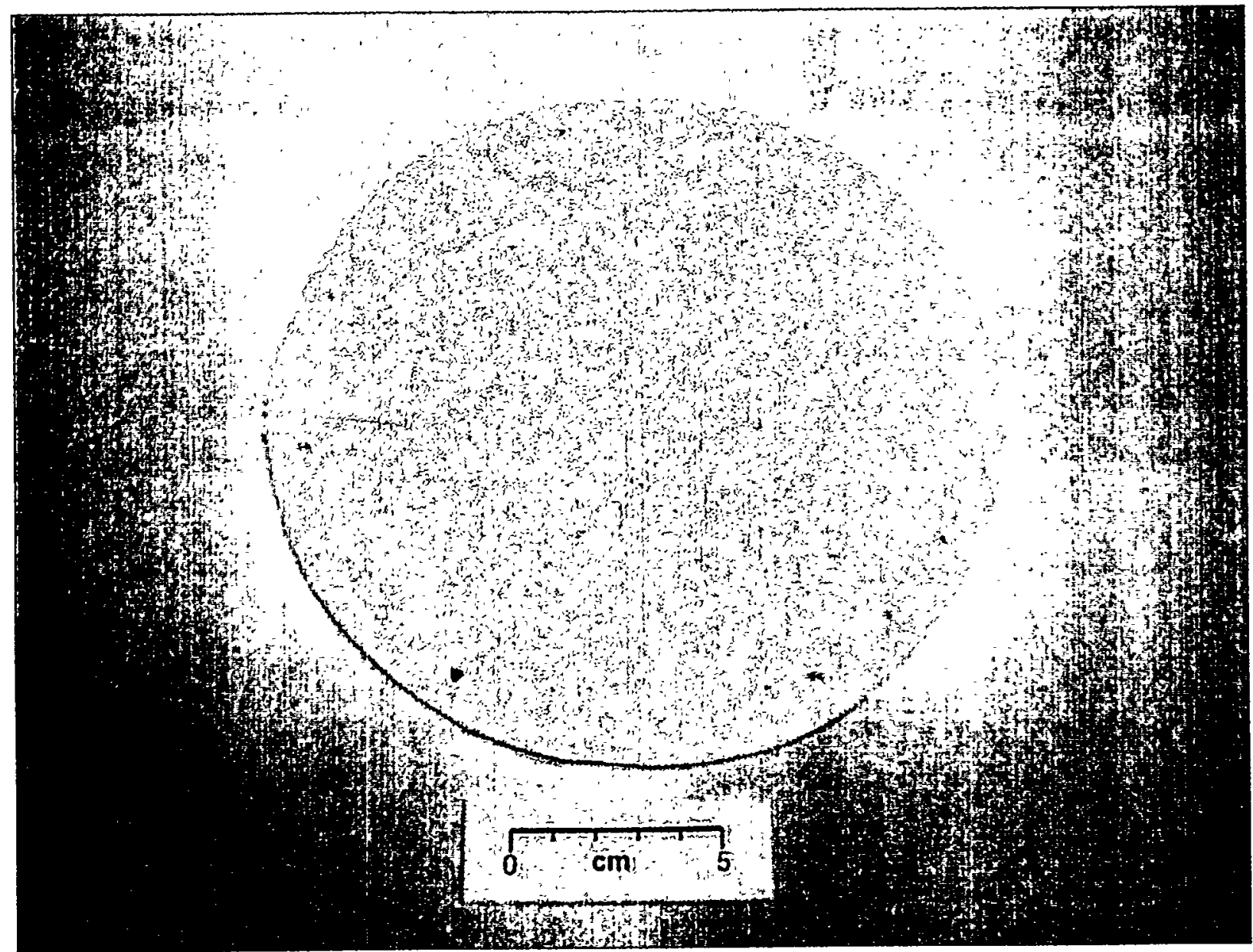

Figure 16 View of the collection side of a "gauze-front" Lepestok filter. The ends of the cloth ties are visible at the left and right edges of the mask. 


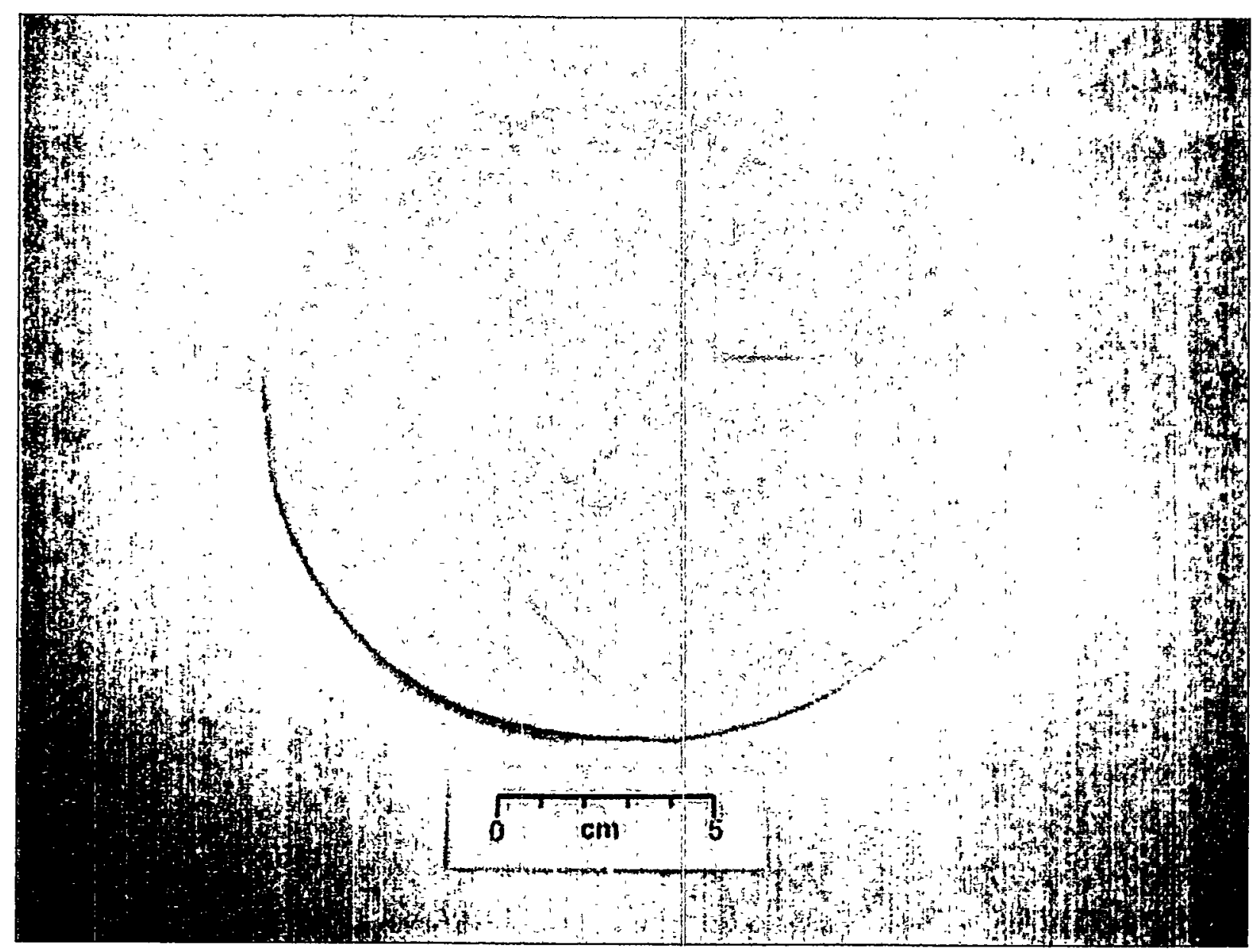

Figure 17 View of the back (face) side of the "gauze-front" Lepestok facemask. The area of the soft metal clip is located at the top edge of the mask. The ends of the elastic pull cords can be seen at the bottom edge of the mask. The star-shaped plastic frame is visible at the center of the mask. The cloth ties are folded over the center area. 


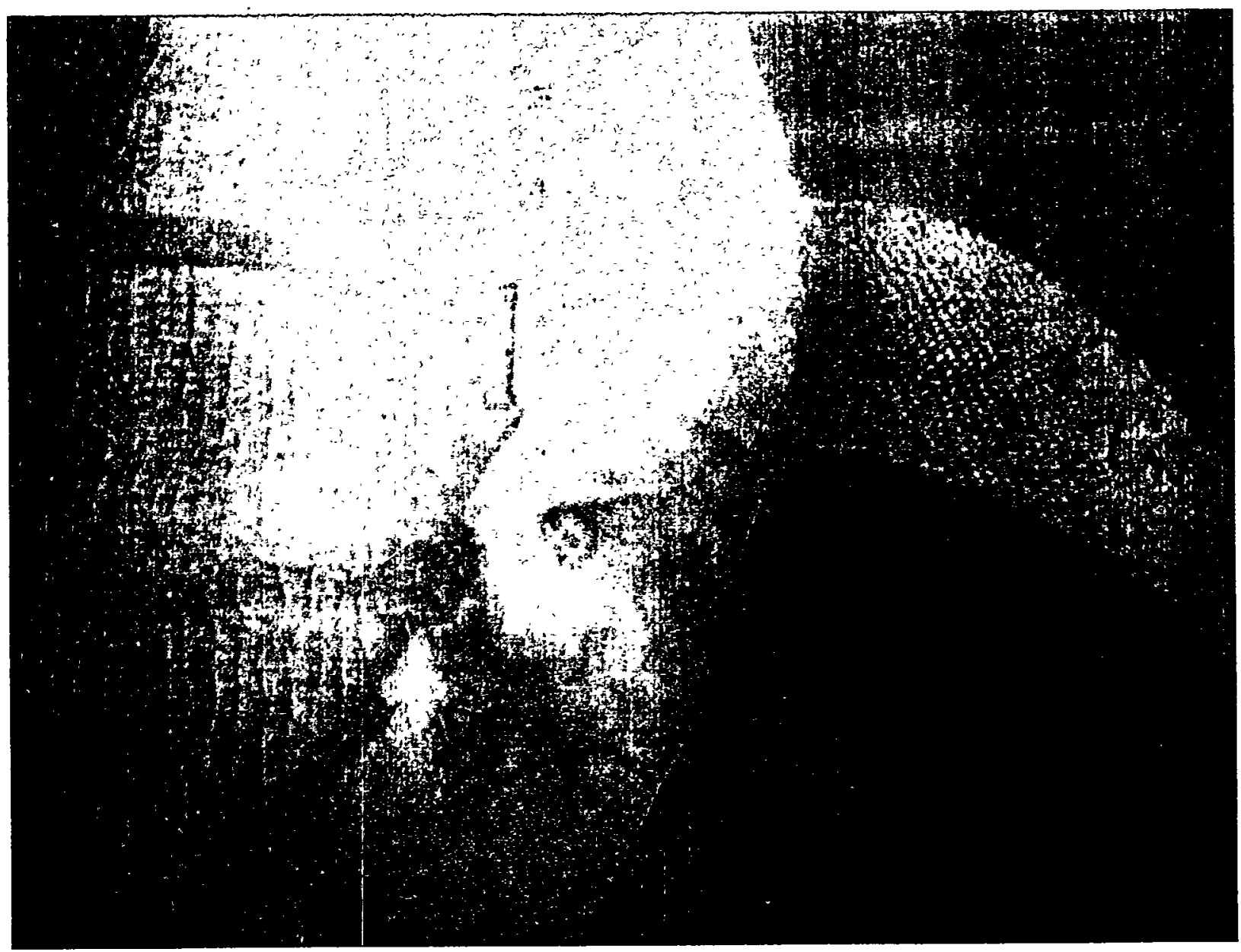

Figure 18 Closer view of the back side of a "gauze-front" Lepestok face mask showing the region where the plastic support frame and the cloth ties are attached to the edge of the mask. The folded material at the edge shows the fine-fiber nature of the collection filter where the front surface of the filter is folded over onto the back side. 


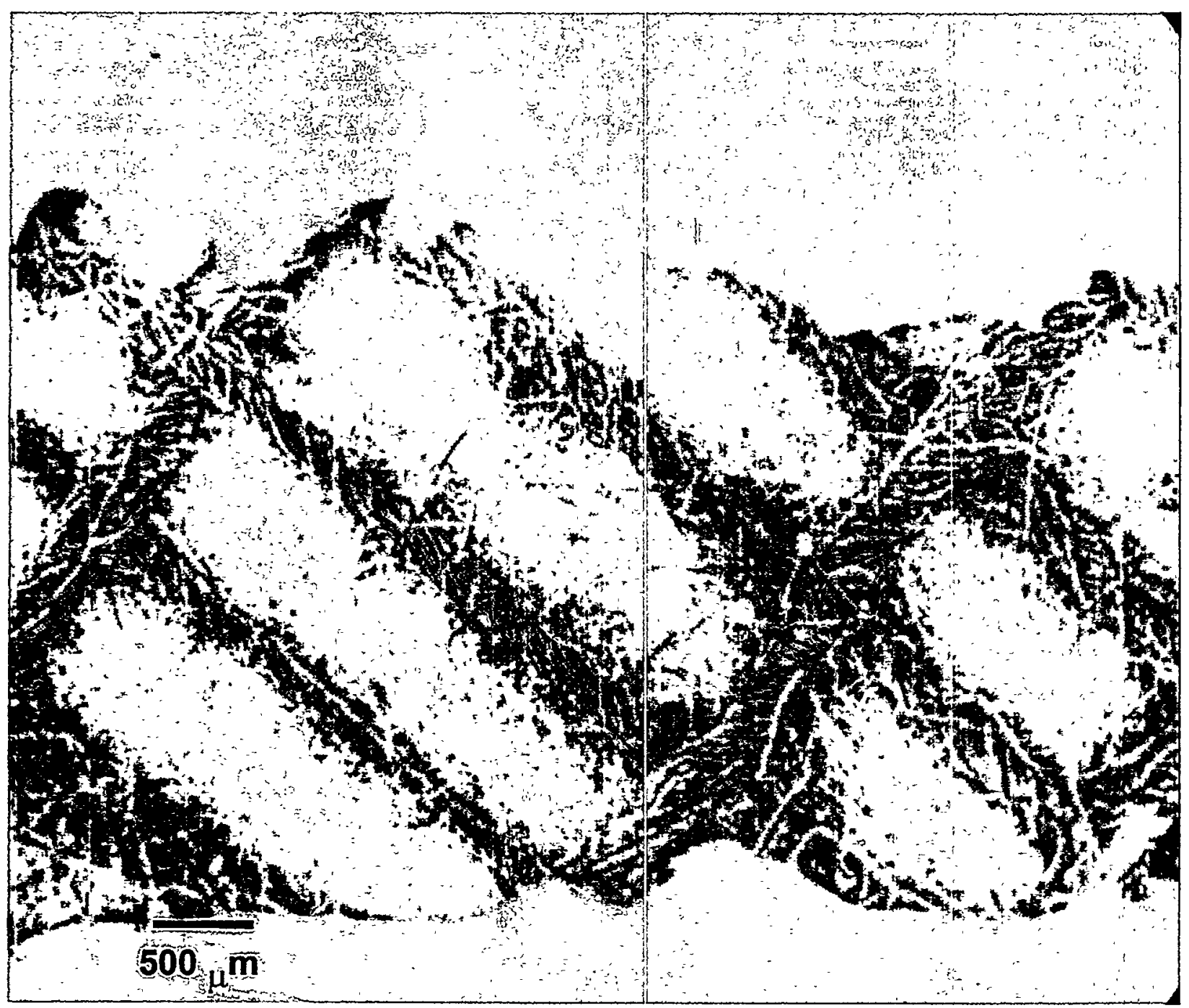

Figure 19 Scanning electron photomicrograph of the aerosol collection side of the "gauze-front" Lepestok face masks. (Magnification is 37X. Scale factor is $27 \mu \mathrm{m} / \mathrm{mm}$. The width of the visible image is $4.5 \mathrm{~mm}$.) The typical diameter of the thread bundles of the gauze is about $0.3 \mathrm{~mm}$. The typical diameter of the individual threads in the gauze fiber bundles is about $10 \mu \mathrm{m}$. Note that the distance between gauze fiber bundles is irregular. 


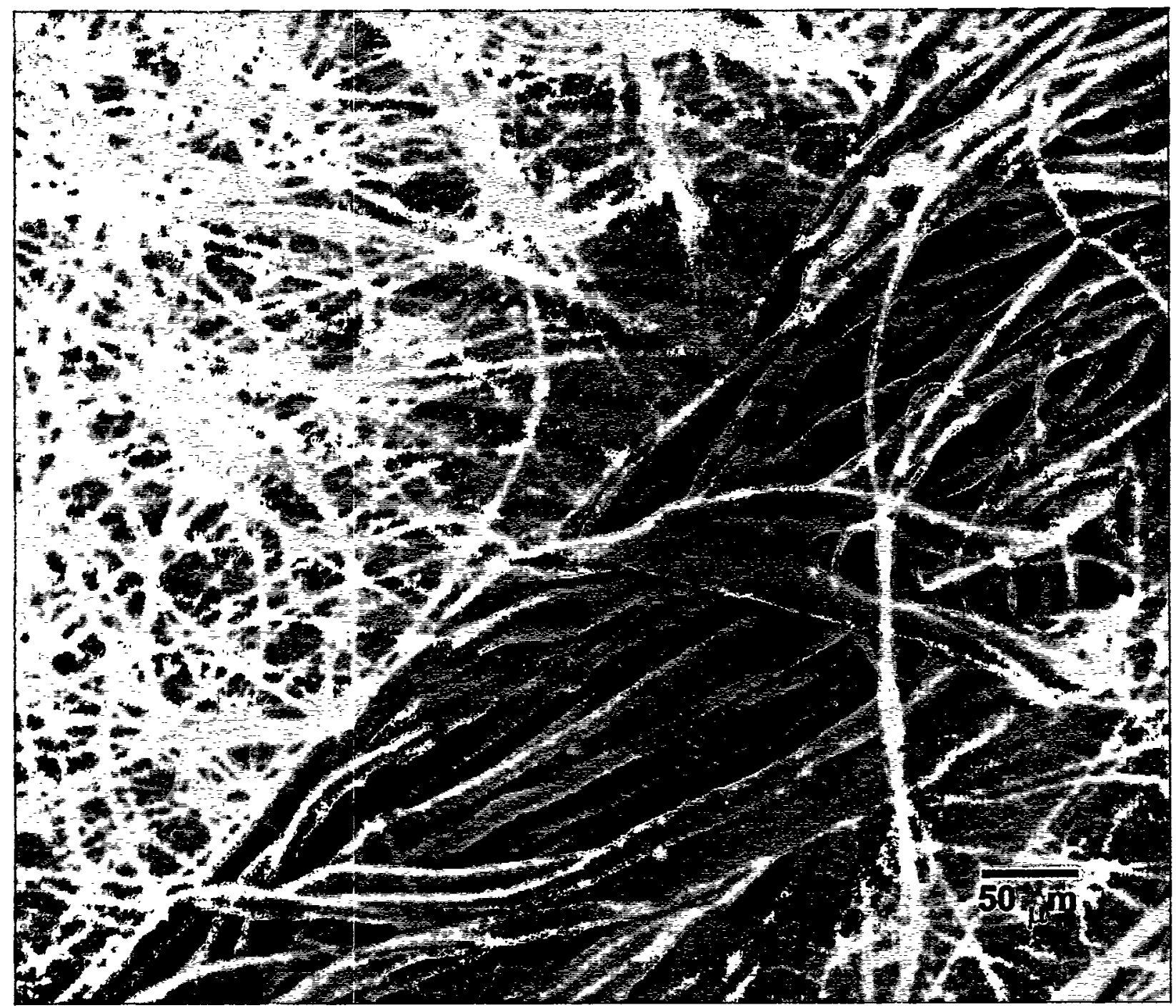

Figure 20 Higher magnification scanning electron photomicrograph of a gauze mesh fiber bundle and the underlying fine-fiber filter matrix on the aerosol collection side of a "gauze-front" Lepestok face mask. (Magnification is 370X. Scale factor is $2.7 \mu \mathrm{m} / \mathrm{mm}$. The width of the visible image is $0.45 \mathrm{~mm}$.) The fine-fiber filter is similar in appearance to the AFA-RMP-20 filter material. 


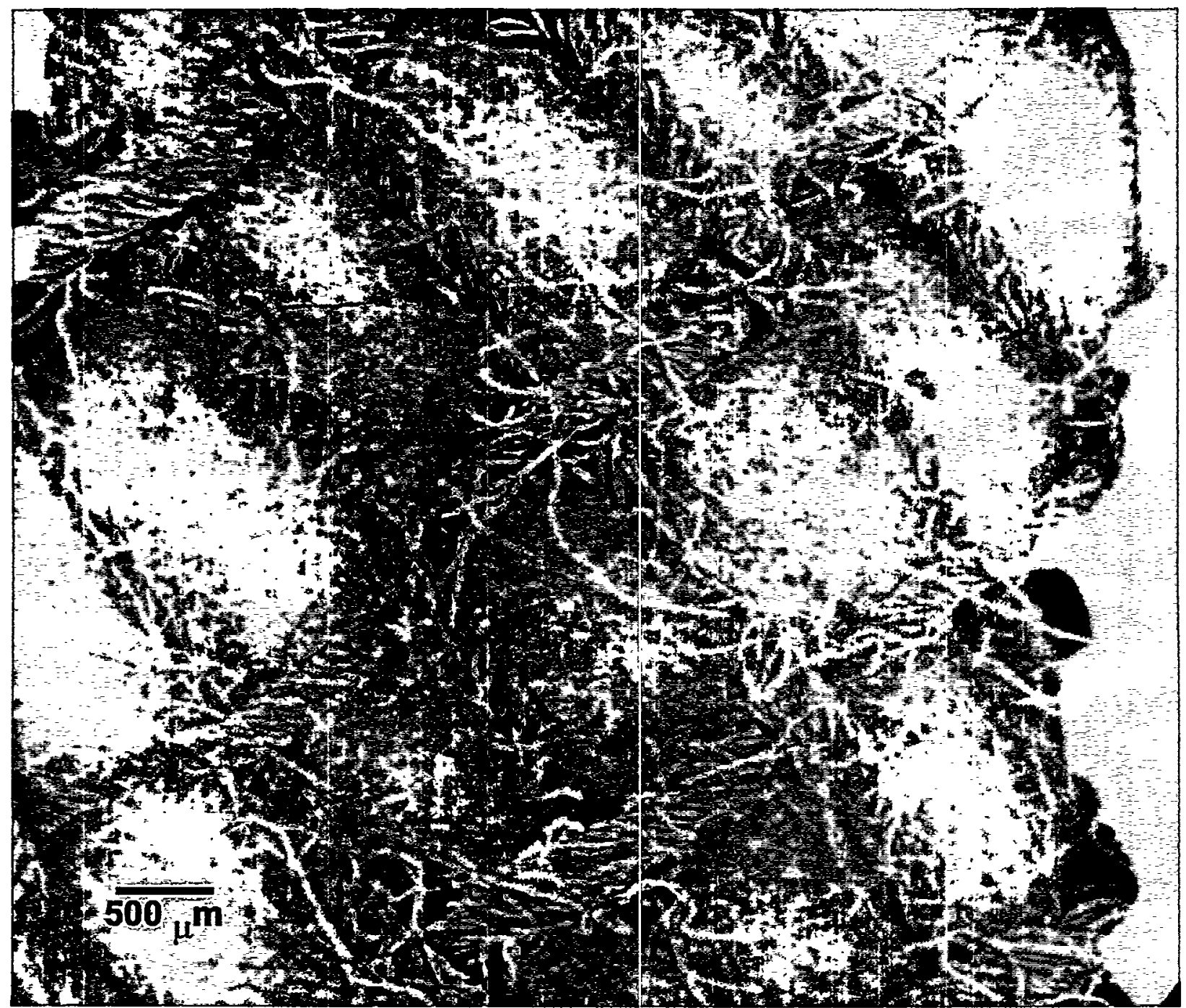

Figure 21 Scanning electron photomicrograph of the gauze support side (backside) of a "gauze-front" Lepestok face mask. (Magnification is 37X. Scale factor is $27 \mu \mathrm{m} / \mathrm{mm}$. The width of the visible image is $4.5 \mathrm{~mm}$.) In the samples examined in this study, the gauze mesh was more uniform on the backside of the facemask than on the front side. 


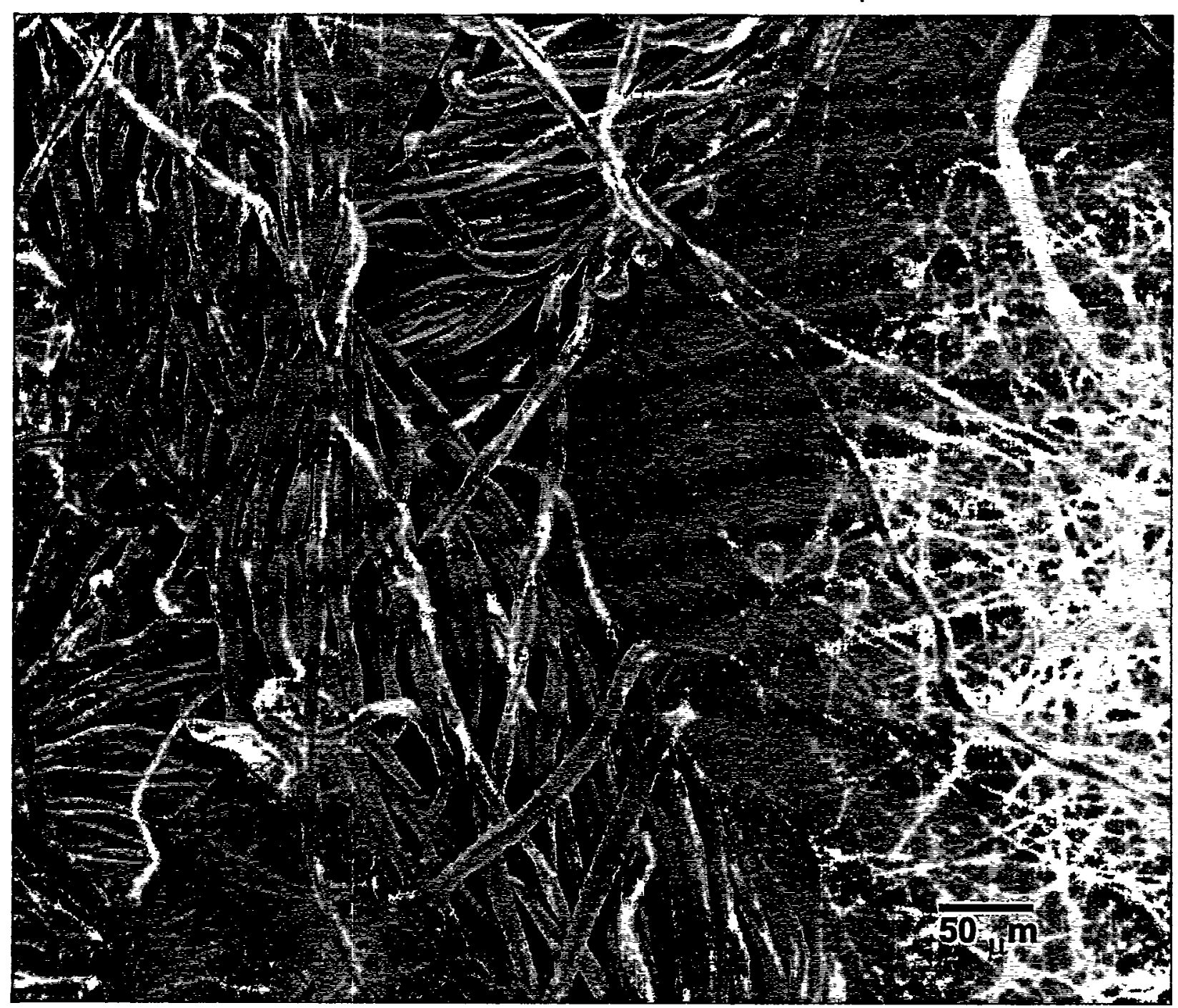

Figure 22 Higher magnification scanning electron photomicrograph of the back (or face-) side of a "gauze-front" Lepestok face mask, showing both the gauze support mesh and the underlying fine-fiber aerosol collection filter. (Magnification is 370X. Scale factor is $2.7 \mu \mathrm{m} / \mathrm{mm}$. The width of the visible image is $0.45 \mathrm{~mm}$.) 


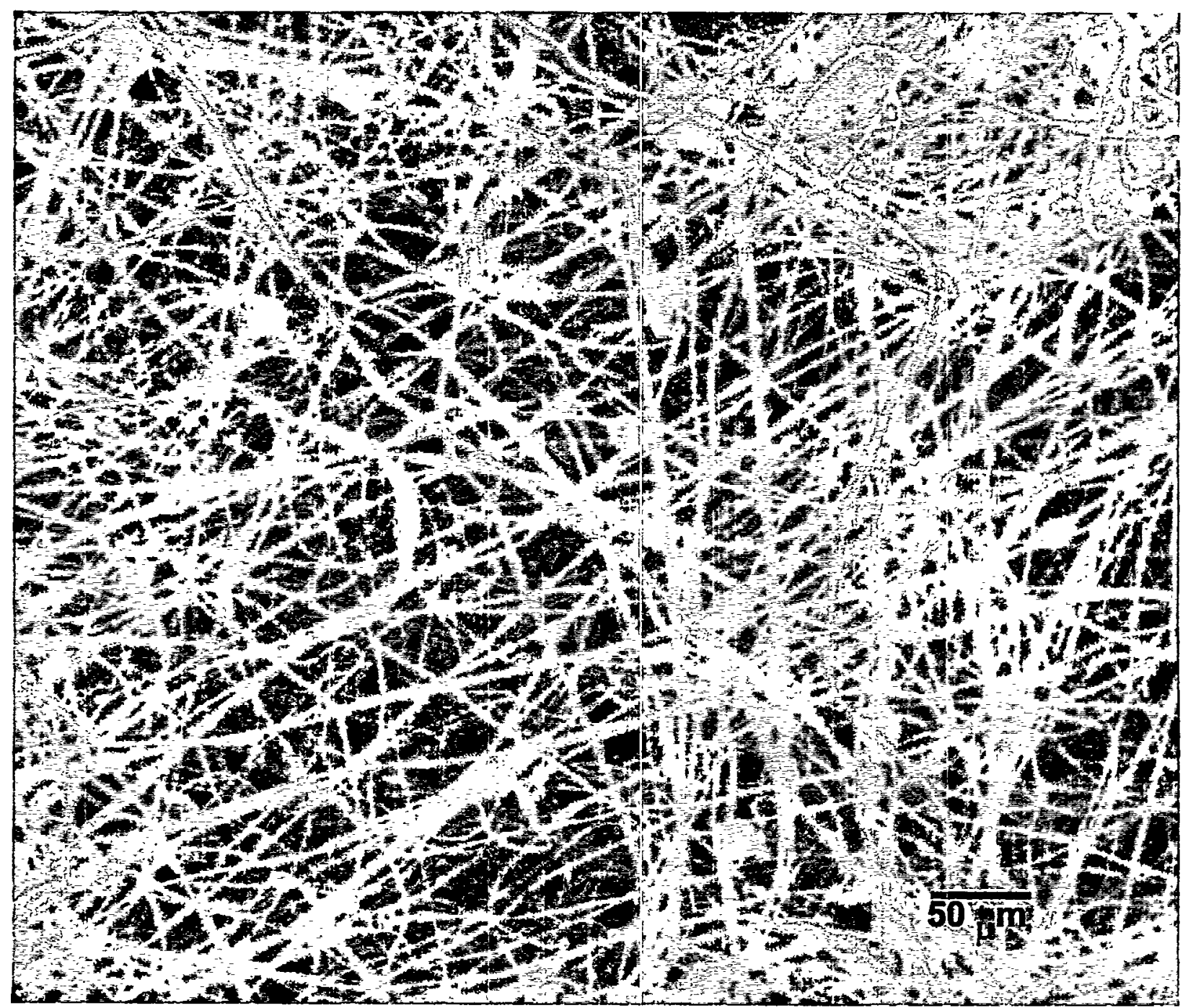

Figure 23 Scanning electron photomicrograplh of the fine-fiber aerosol collection filter surface (without the gauze support mesh) on the back or face-side of a "gauze-front" Lepestok face mask. (Magnification is 370X. Scale factor is $2.7 \mu \mathrm{m} / \mathrm{mm}$. The width of the visible image is $0.45 \mathrm{~mm}$.) 


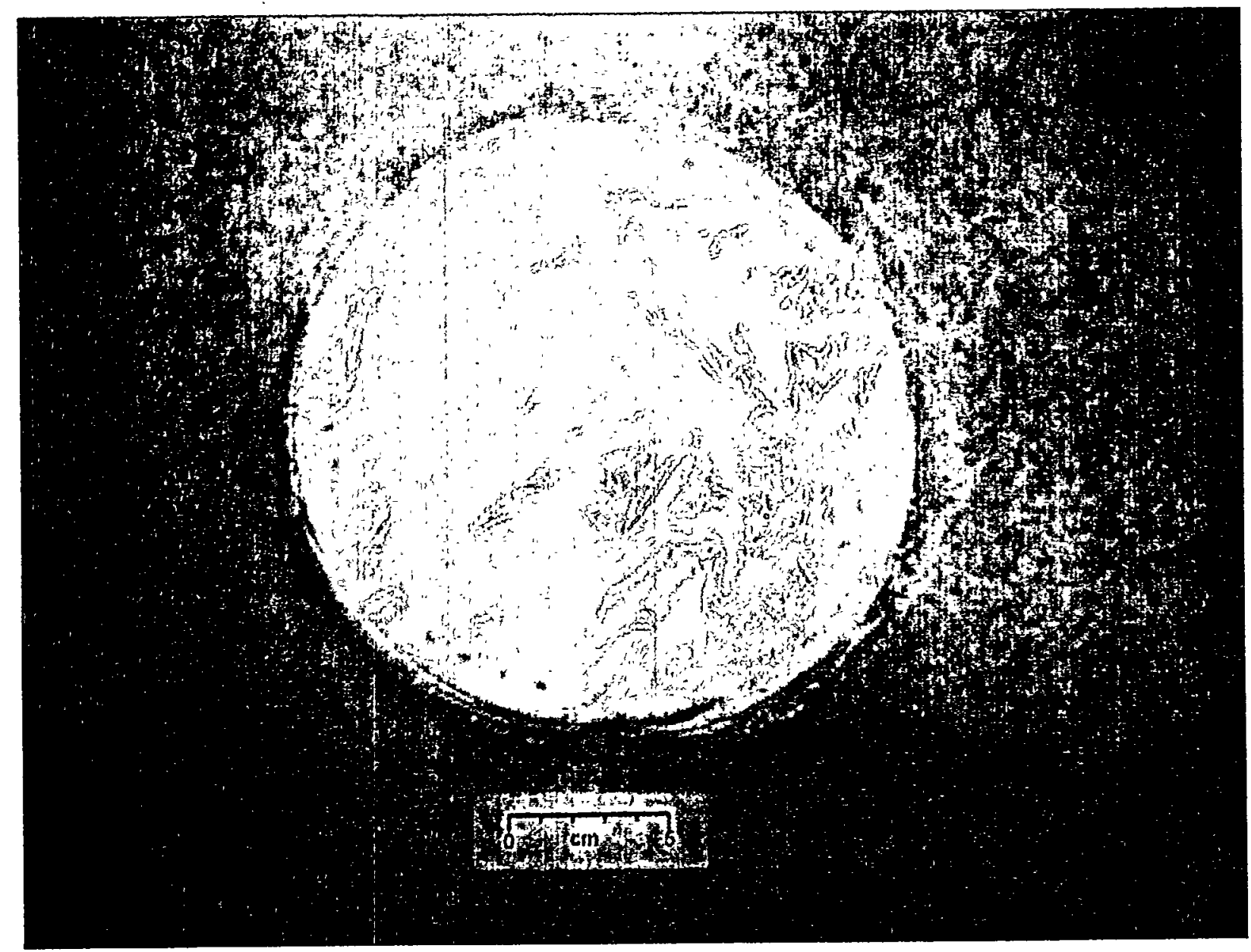

Figure 24 View of a package of "fiber-front" Lepestok face masks. 


\section{FIBER-FRONT FACE MASK}

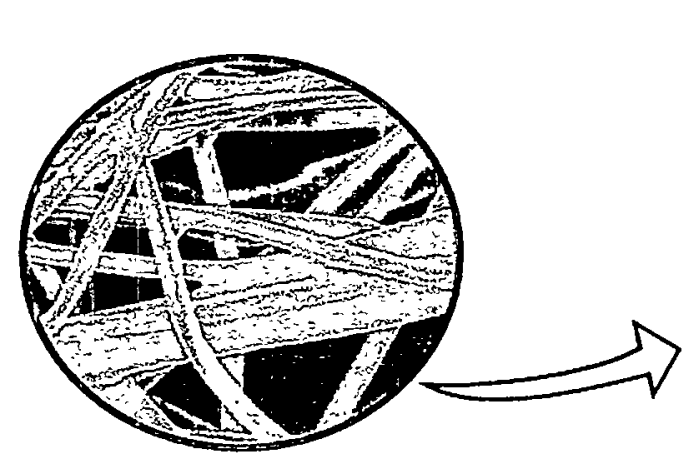

Fiber Front Layer
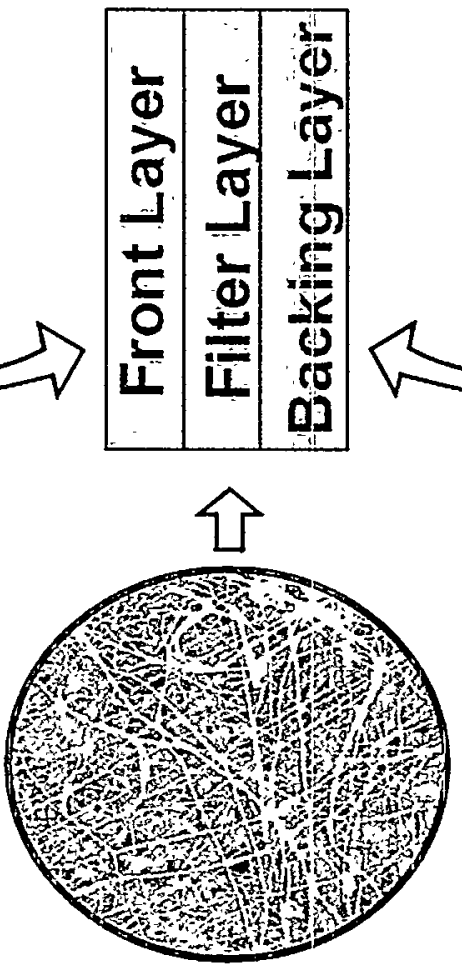

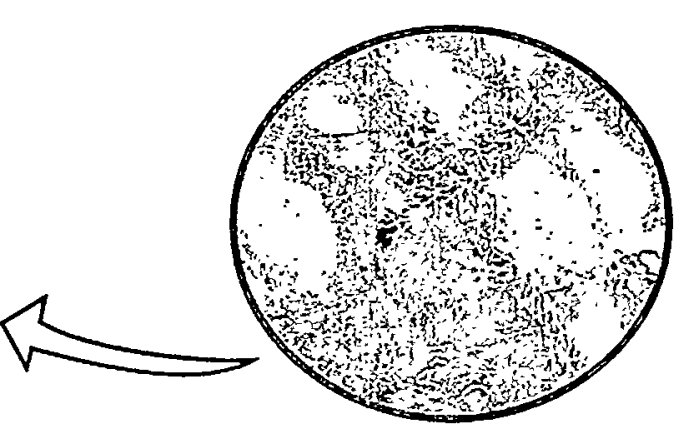

Gauze Backing Layer

Respirator Fiber Filter Layer

Figure 25 Schematic diagram of the construction of the "fiber-front" Lepestok facemask. The filter layer is protected on the fromt side by a coarse fiber filter media and supported on the backside by gauze. The gauze layer and filter layer are similar to the gauze and filter materials used in the AFA-RMP-20 fiber-type analytical filter. 


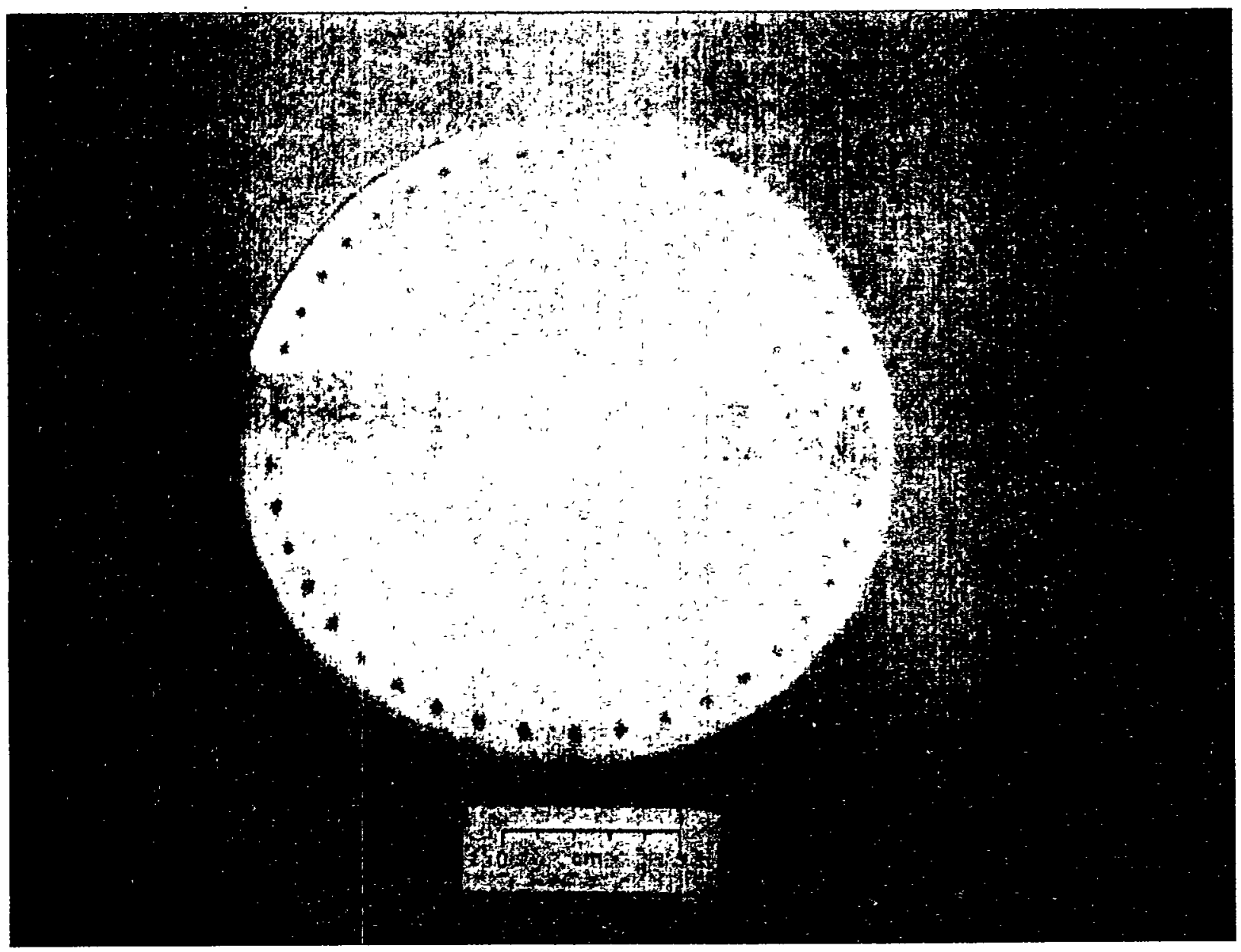

Figure 26 View of the front of a "fiber-front" Lepestok facemask. Note that the cloth tie feature is a single, continuous strip of cloth that is mounted between the front prefilter layer and the collection filter layer. 


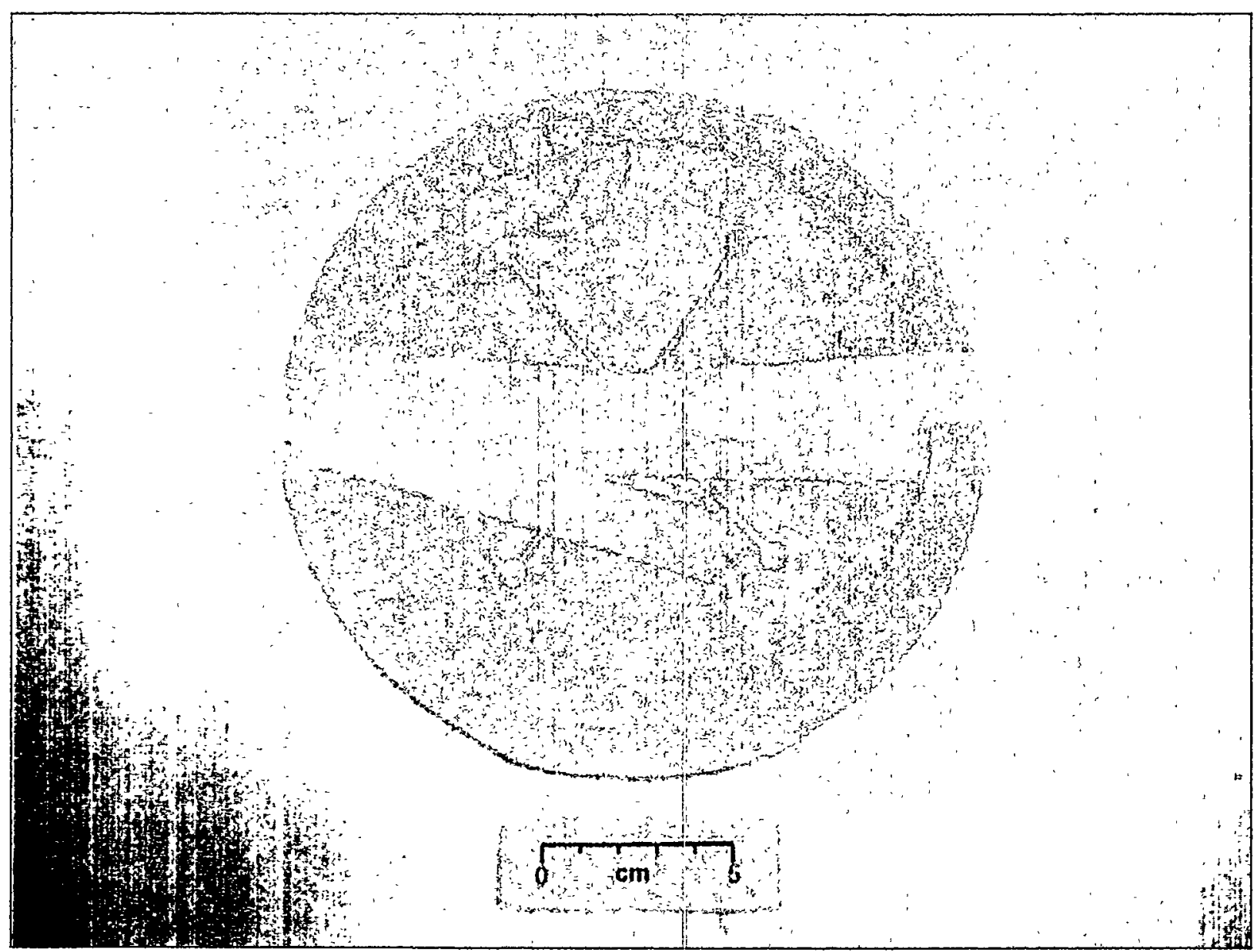

Figure 27 View of the face side of the "fiber-fiont" Lepestok facemask. The nose clip is located in the lower edge, the elastic pulls are located in the top edges, and the plastic frame and the neck ties are seen at the center. 


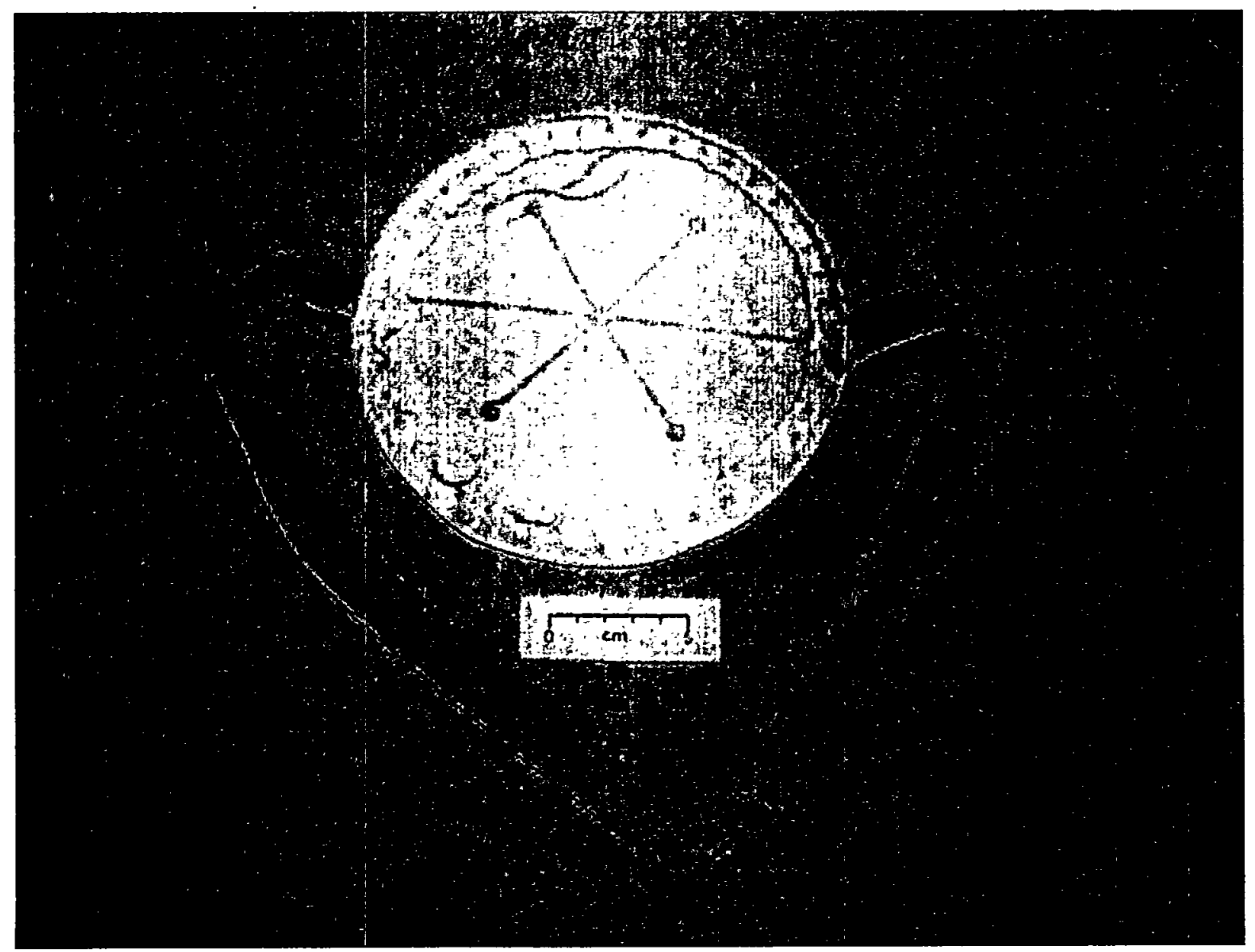

Figure 28 View of the "fiber-front" Lepestok facemask ready for adjusting and attaching to the face. 


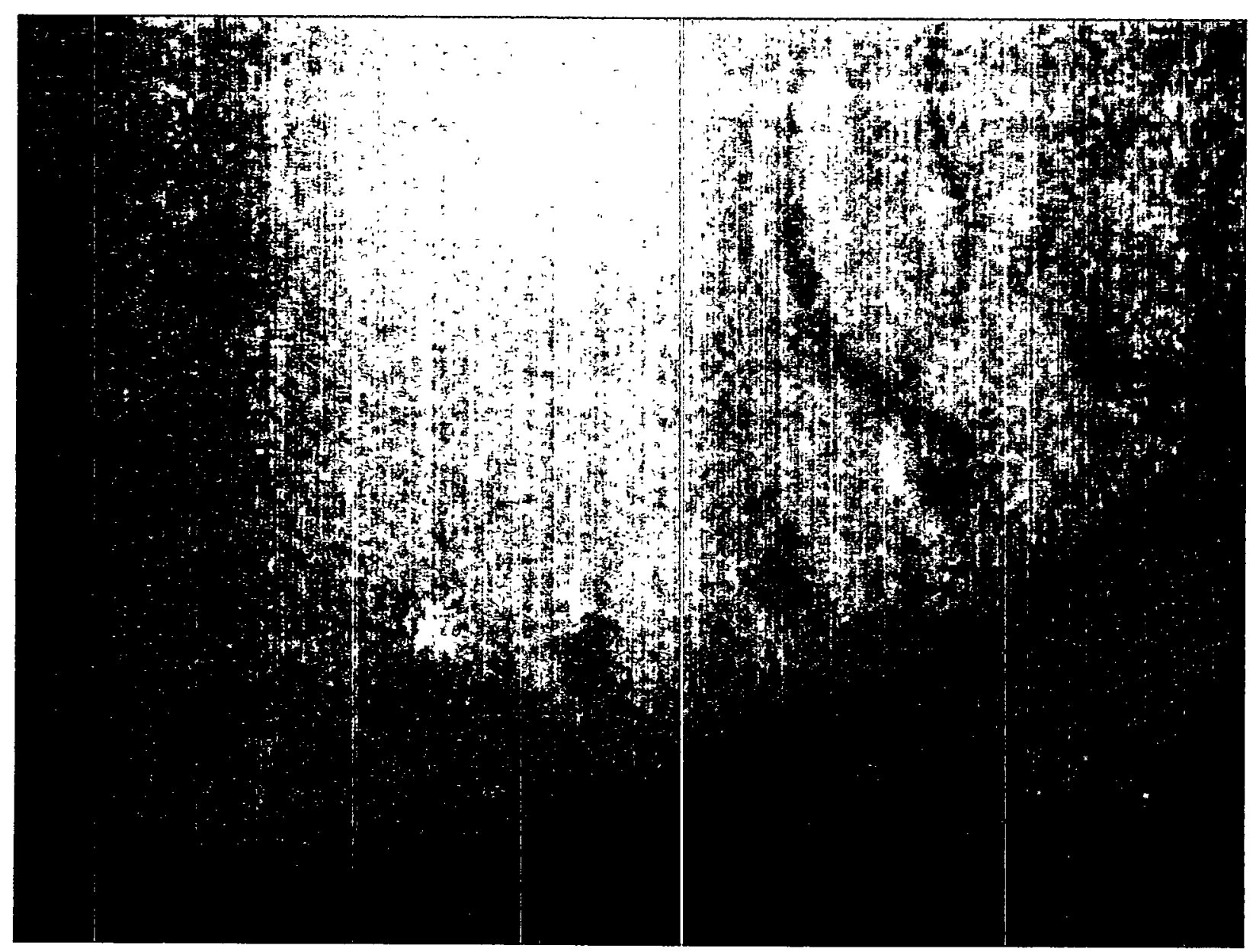

Figure 29 View of the backside of a "fiber-front" Lepestok facemask, showing the elastic pull cords. 


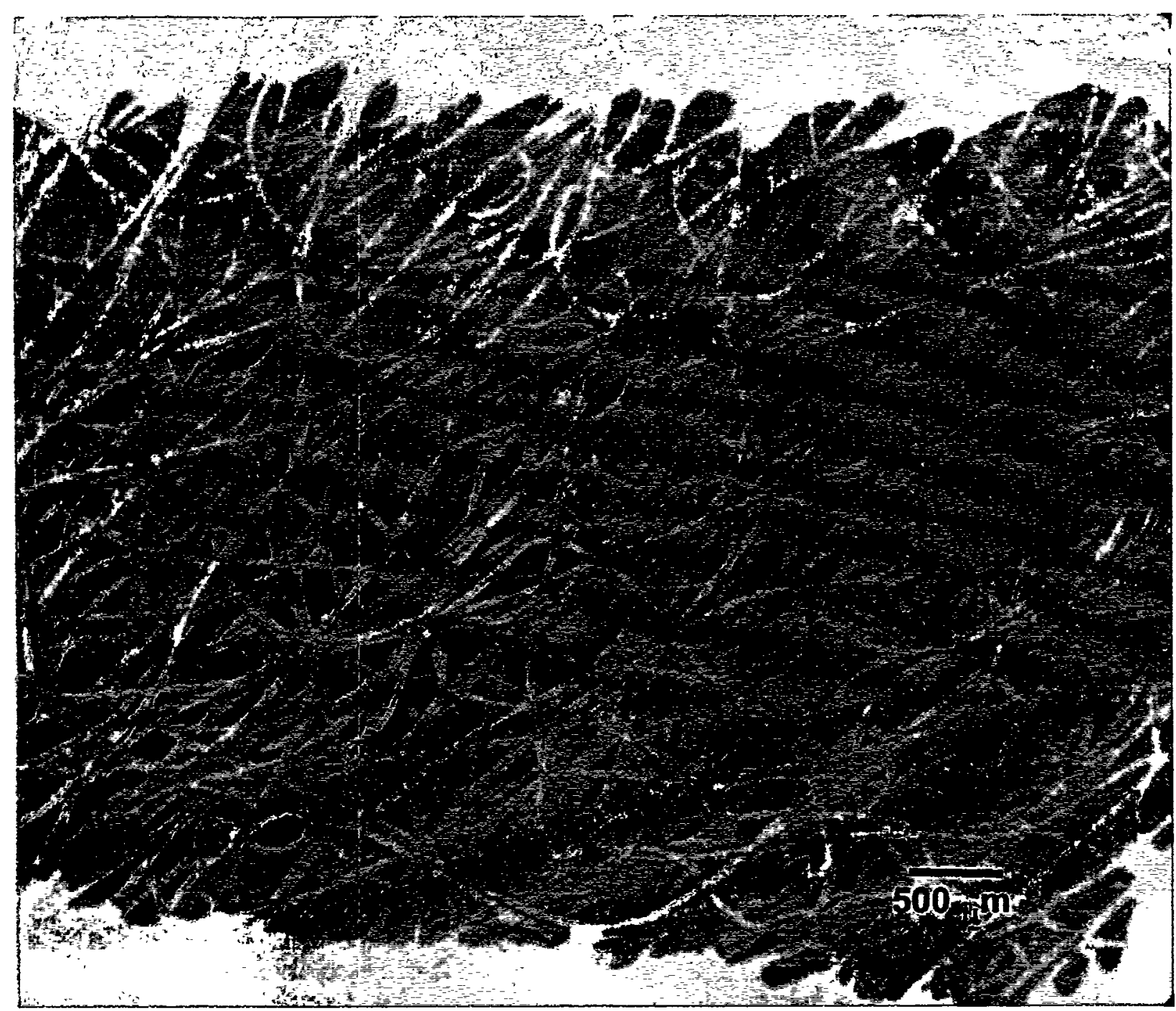

Figure 30 Low magnification scanning electron photomicrograph of the aerosol collection side of the "fiber-front" Lepestok facemask. (Magnification is 37X. Scale factor is $27 \mu \mathrm{m} / \mathrm{mm}$. The width of the visible image is $4.5 \mathrm{~mm}$.) The typical diameter of the coarse fibers in the fibrous prefilter is about $45 \mu \mathrm{m}$. The actual aerosol collection filter is barely visible beneath the fibrous prefilter. 


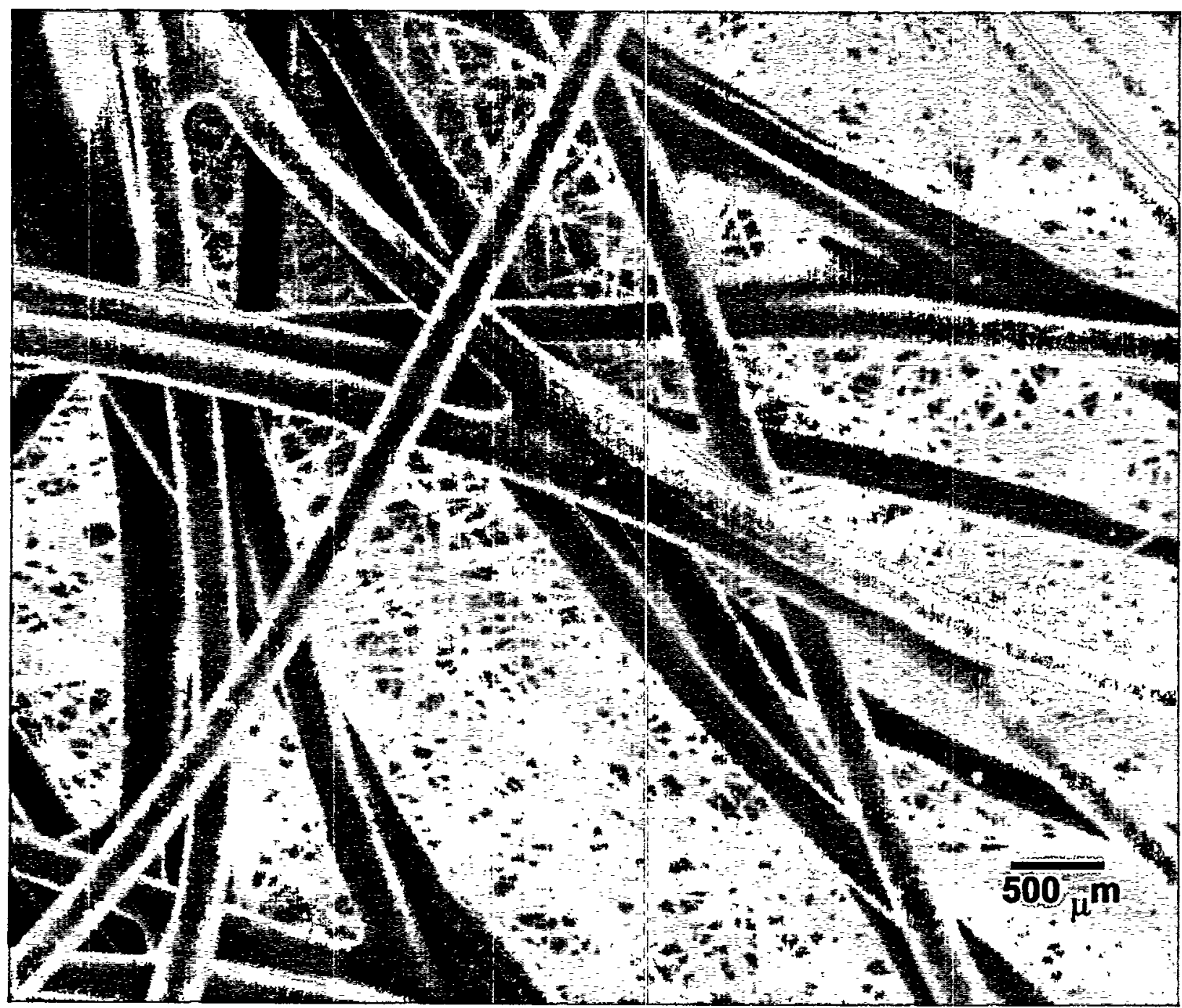

Figure 31 Higher magnification scanning electron photomicrograph of the aerosol collection side of the "fiber-front" Lepestok face mask. (Magnification is 370X. Scale factor is $2.7 \mu \mathrm{m} / \mathbf{m m}$. The width of the visible image is $0.45 \mathrm{~mm}$.) The fiber diameter of the prefilter is approximately an order of magnitude greater than the fiber diameter of the aerosol collection filter. 


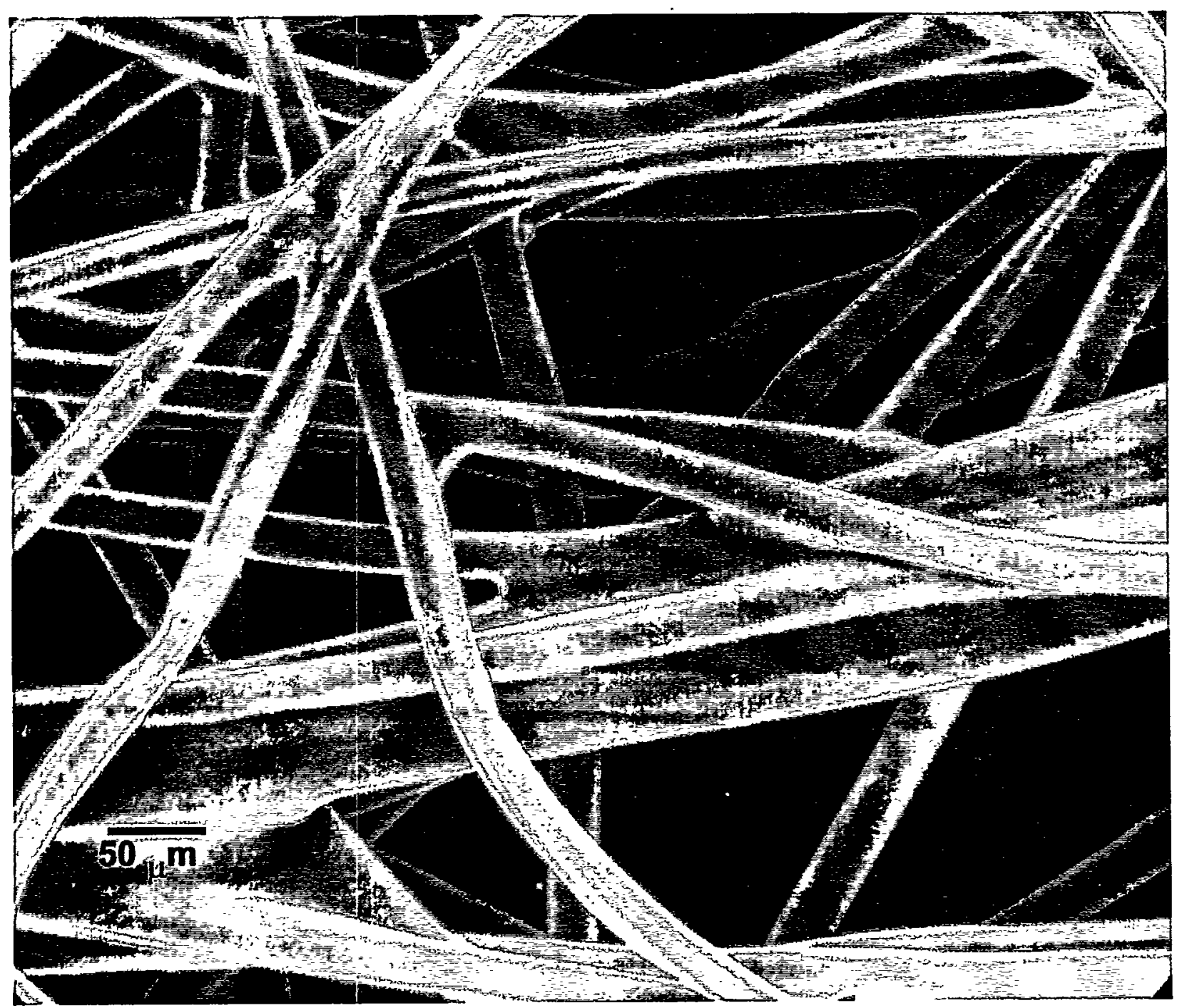

Figure 32 Scanning electron photomicrograph of the fibrous prefilter (with the underlying aerosol collection filter removed) from a "fiber-front" Lepestok facemask. (Magnification is 370X. Scale factor is $2.7 \mu \mathrm{m} / \mathrm{mm}$. The width of the visible image is 0.45 mm.) The fibrous prefilter does not contribute to aerosol collection. 


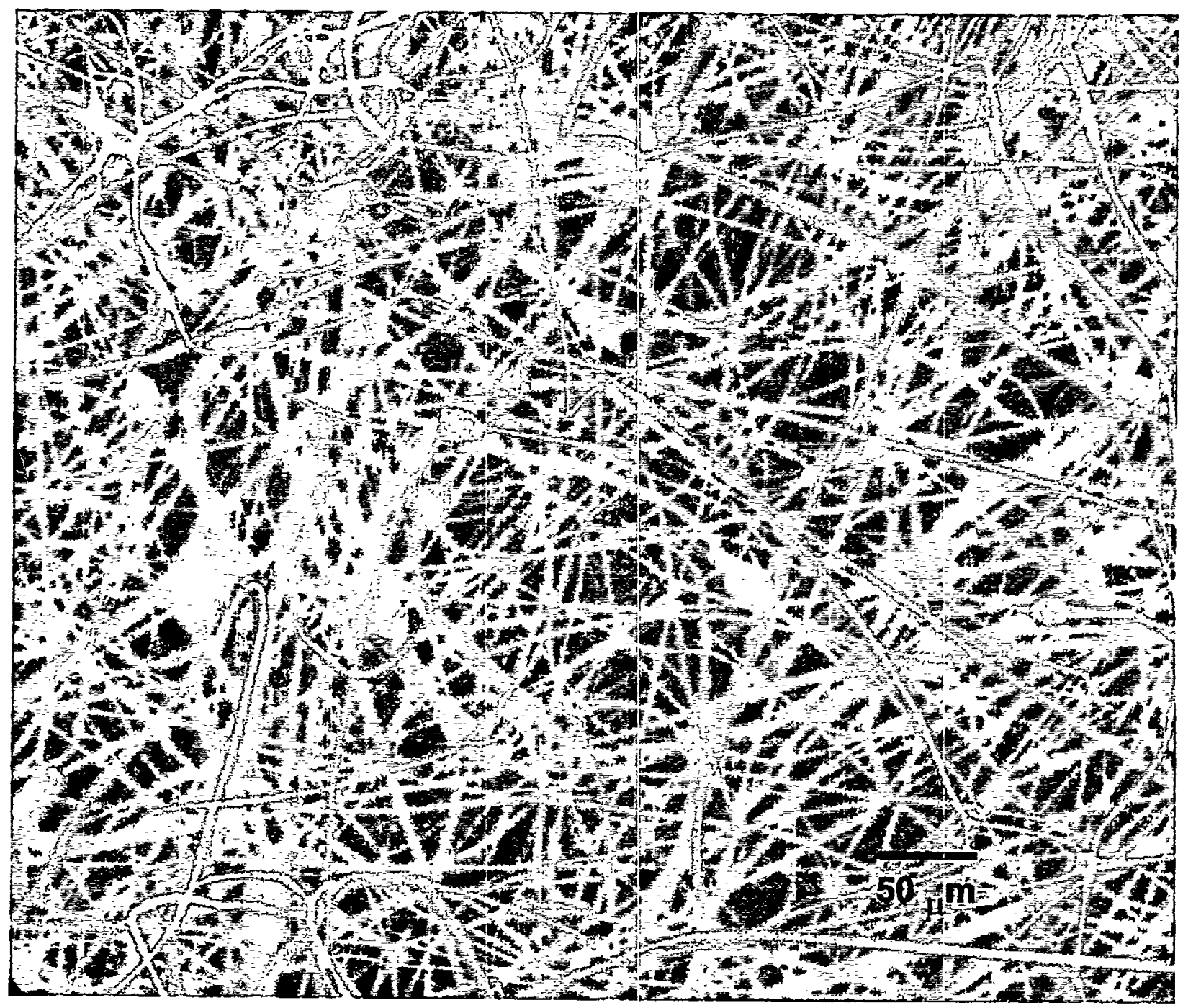

Figure 33 Scanning electron photomicrograph of the aerosol collection filter (with the fibrous prefilter removed) on the front side of the "fiber-front" Lepestok facemask. (Magnification is 370X. Scale factor is $2.7 . \mu \mathrm{m} / \mathrm{mm}$. Width of the visible image is 0.45 mm.) The collection filter has a similar morphology to the filter material in the AFA-RMP20 analytical filters and in the "gauze-front" Lepestok face masks. 


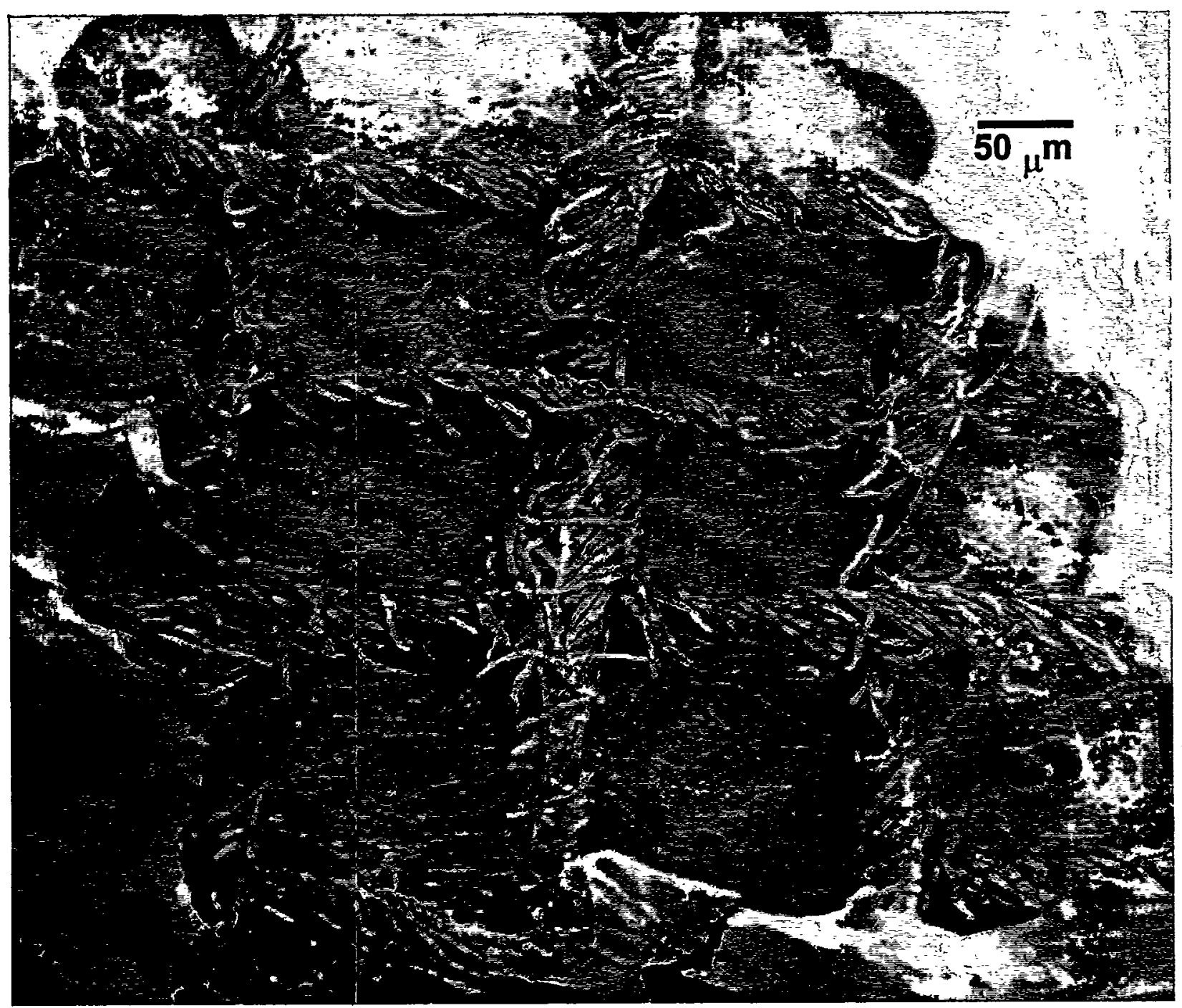

Figure 34 Scanning electron photomicrograph of the gauze support on the back or face-side of the "fiber-front" Lepestok face mask. (Magnification is 370X. Scale factor is $2.7 \mu \mathrm{m} / \mathrm{mm}$. The width of the visible image is $0.45 \mathrm{~mm}$.) The face side of the "fiber-front" Lepestok facemask is similar to the face side of the "gauze-front" Lepestok facemask. 


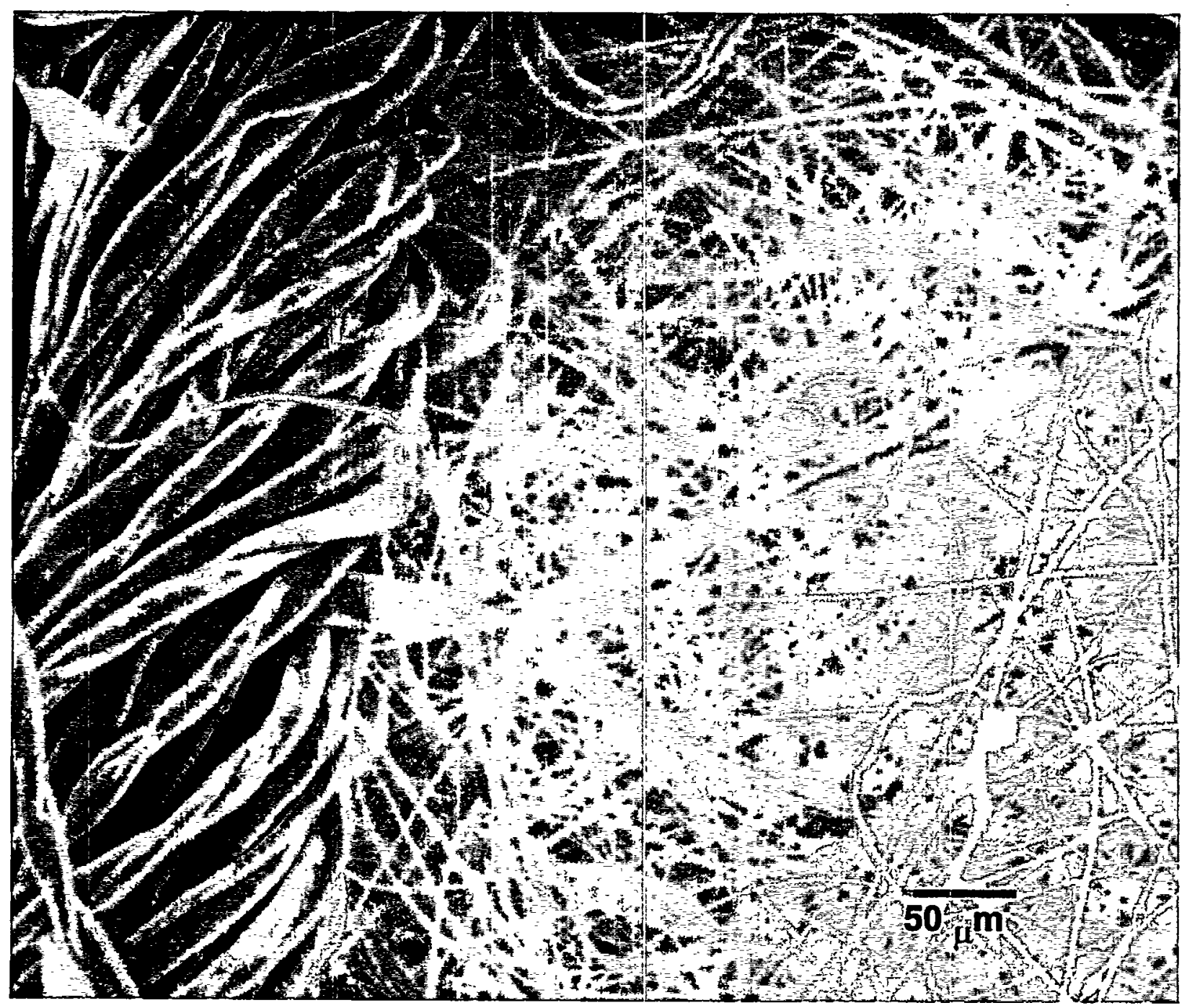

Figure 35 Higher magnification scanning electron photomicrograph of the gauze support mesh and the aerosol collection filter on the back or face-side of the "fiber-front" Lepestok face mask. (Magnification is 370X. Scale factor is $2.7 \mu \mathrm{m} / \mathrm{mm}$. The width of the visible image is $0.45 \mathrm{~mm}$.) 
PNNL Filter and Fluoropore Filter Spectra Total Counts: 51,531 PNNL Filter

53,851 Fluoropore Filter

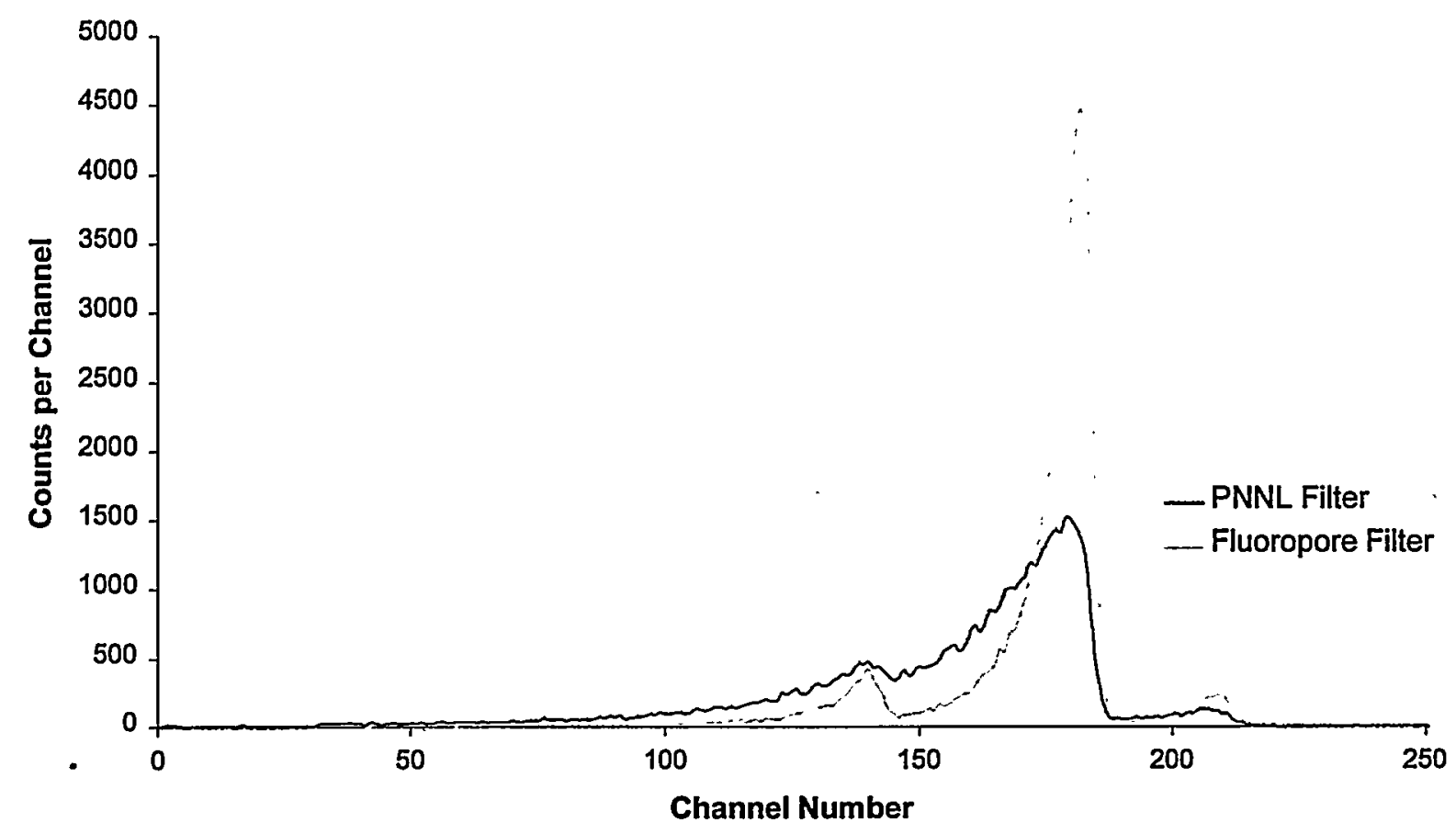

Figure 36 Comparison of the alpha energy spectrum from ambient radon progeny collected in an Eberline Alpha-6 alpha continuous air monitor with a 1-inch diameter detector and a 1-inch diameter collection area for (red, the sharper peaked spectrum) a Millipore Fluoropore 5- $\mu \mathrm{m}$ pore size Teflon membrane filter (an excellent front surface collecting filter) and for (blue, the much broader spectrum) an AFA-RMP-20 analytical filter. The fibrous nature of the AFA-RMP-20 filter provides a "depth filter" rather than the "front-surface collecting filter". The alpha energy spectrum of the AFA-RMP-20 is similar to that of other glass fiber filters, such as the Whatman EPM-2000. 


\section{PNNL Filter Spectrum Side B}

Total Counts: 33,227

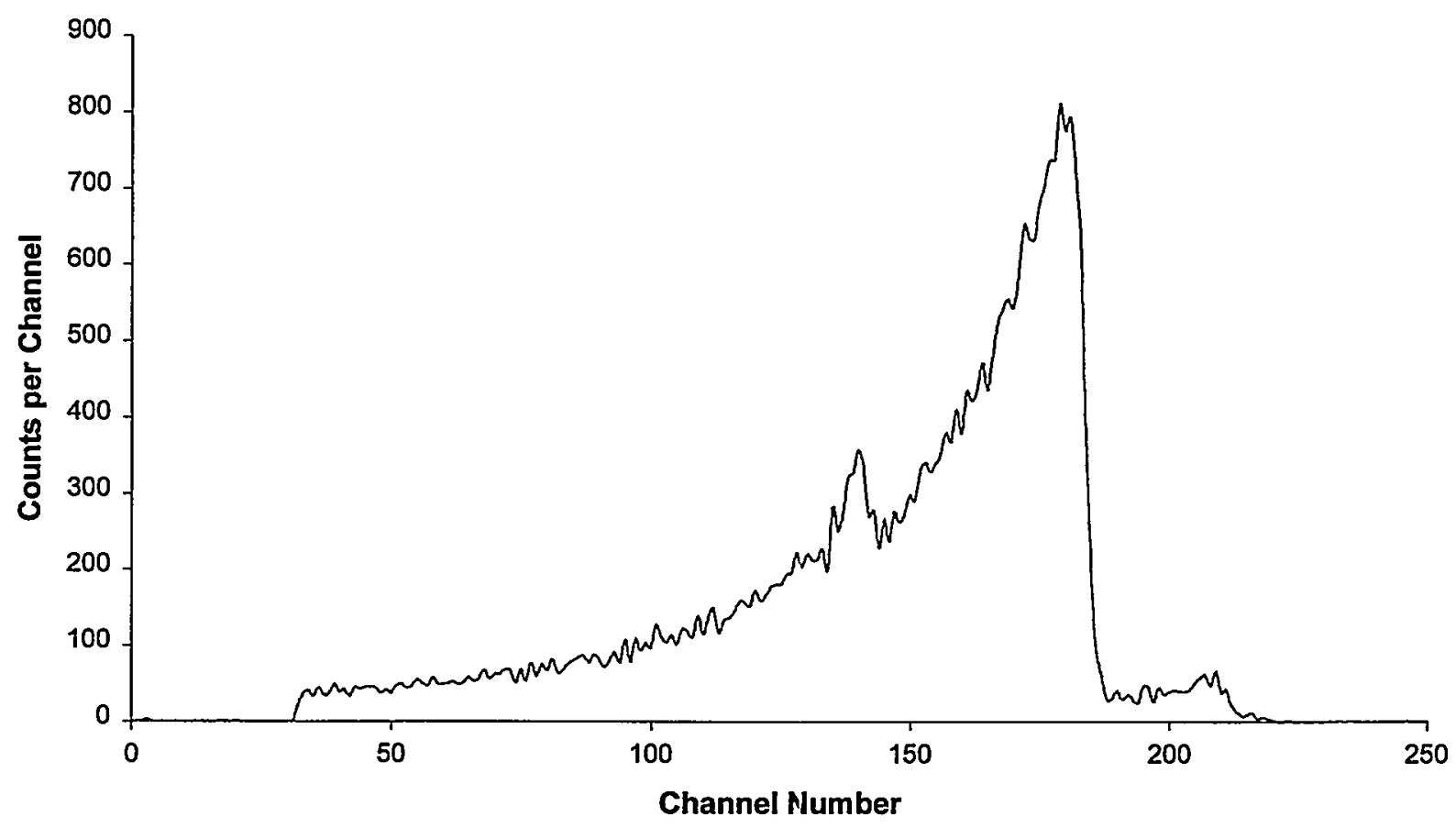

Figure 37 Alpha energy spectrum for ambient radon progeny collected on the back surface (with the gauze mesh support) of an AFA-RMP-20 analytical filter. The presence of the gauze mesh on the backside of the filter makes the alpha energy spectrum somewhat broader that the spectrum from the collection filter alone. 
PNNL "Gauze-Front" Face Mask Spectrum

Total Counts: 71,921

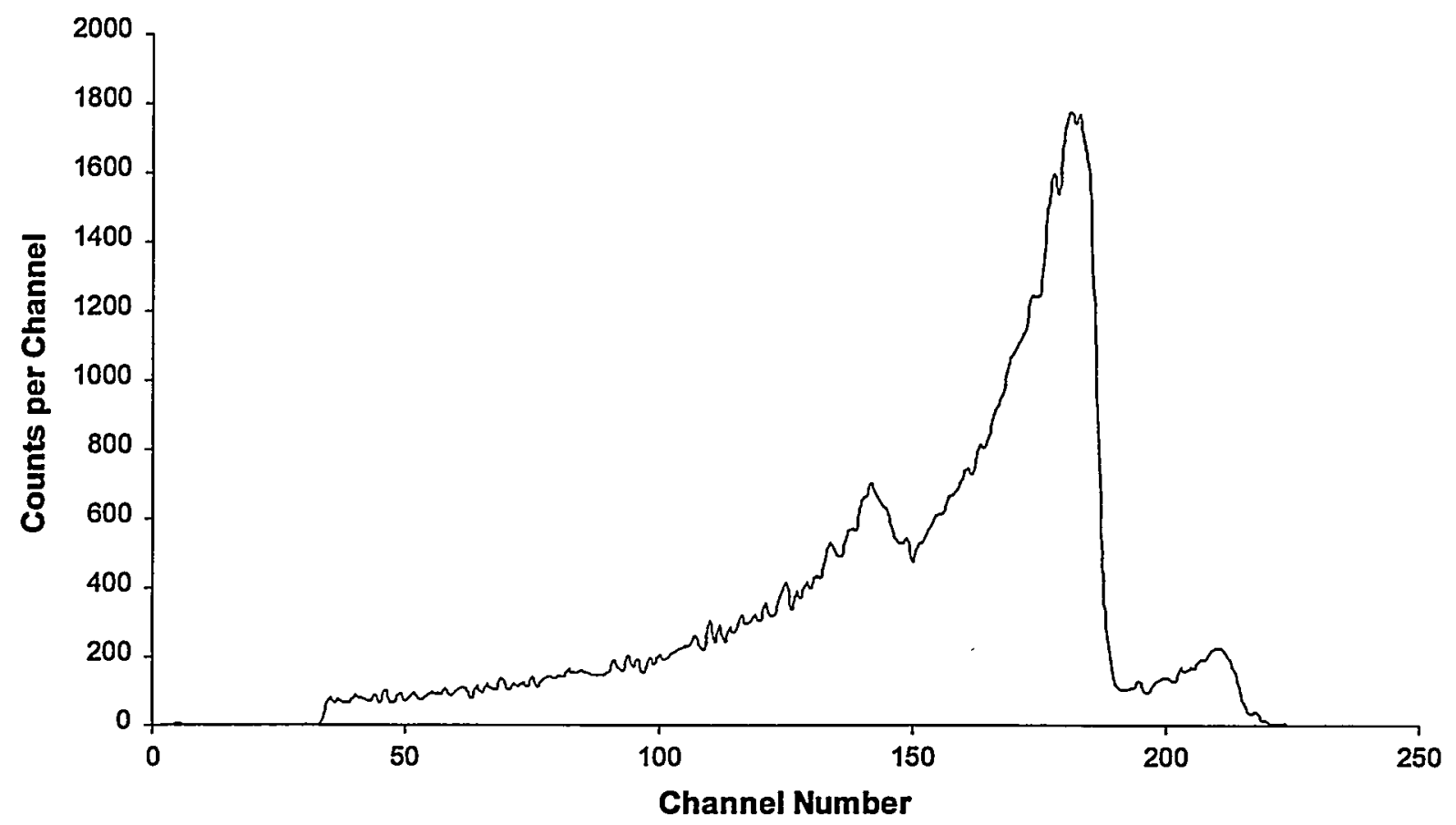

Figure 38 Alpha energy spectrum for ambient radon progeny collected on the front surface of the "gauze-front" Lepestok facemask. The shape of the alpha energy spectrum is similar to that achieved on the back surface (with the gauze mesh support) of an AFARMP-20 analytical filter. 
PNNL "Fiber-Front" Face Mask Spectrum

Total Counts: 66,751

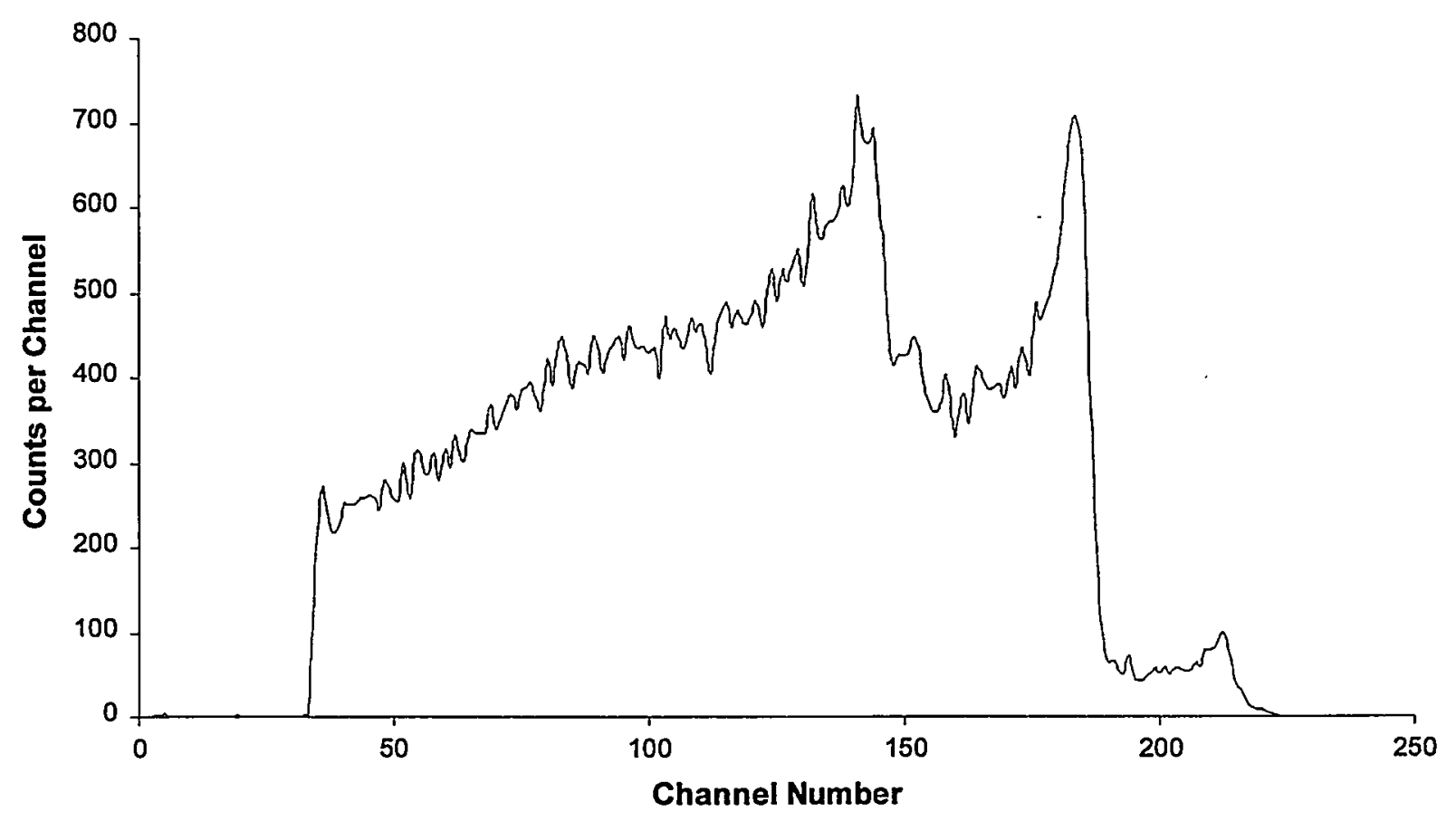

Figure 39 Alpha energy spectrum for ambient radon progeny collected on the front surface of a "fiber-front" Lepestok facemask. The presence of the fibrous prefilter makes the energy spectrum much broader than was achieved with the "gauze-front" Lepestok face mask and with the back surface (with the gauze mesh support) or the front surface of an AFA-RMP-20 analytical filter. The broadening of the energy spectrum is due to the attenuation of the alpha energy as the alpha particle travels from the surface of the filter past (and partially through) the prefilter materiall. 


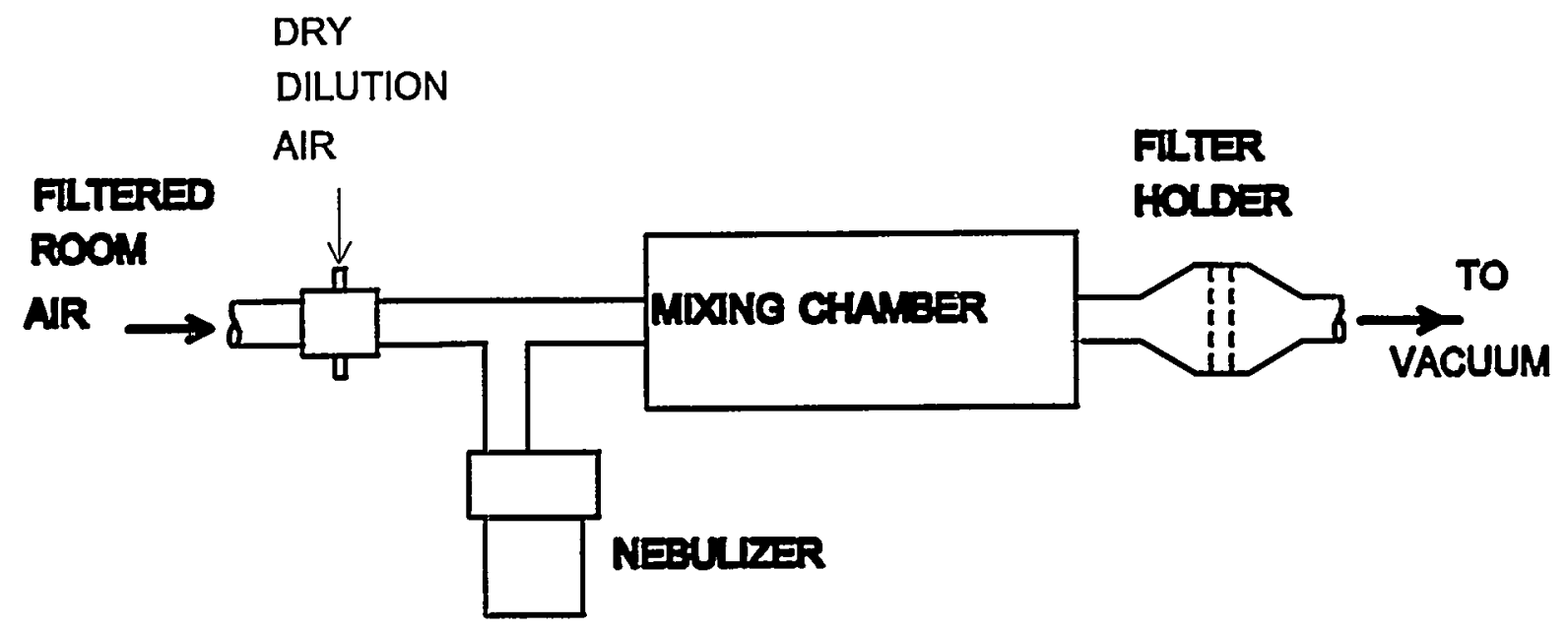

Figure 40 Schematic diagram of the aerosol generation and collection system used for the filter efficiency study. 


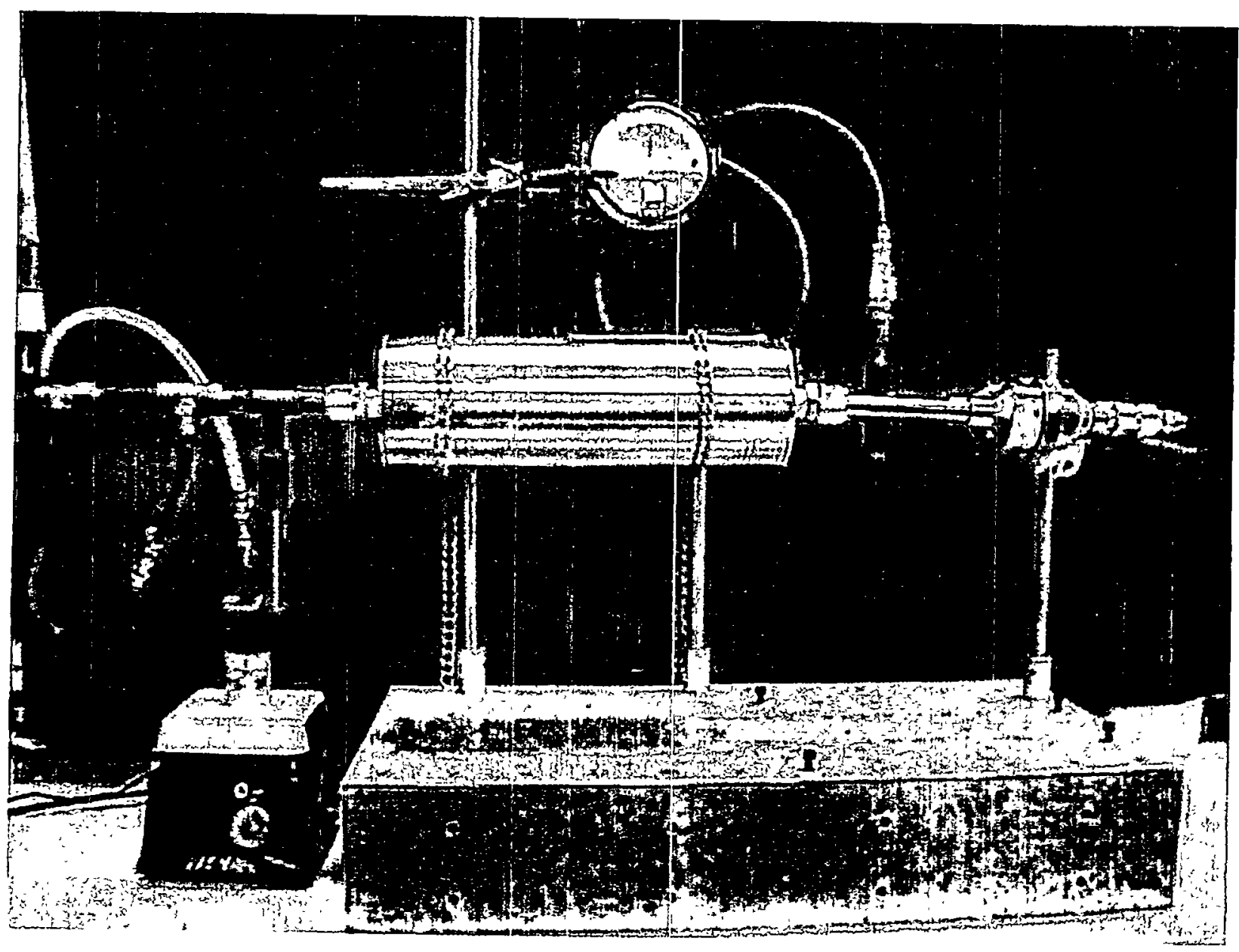

Figure 41 Photograph of the aerosol generation and collection system used for the filter efficiency study. The Lovelace nebulizer is on the left, the aerosol mixing and buffer chamber is in the center, the chamber pressure sensor is located above, and the test filter holders are located on the right. 


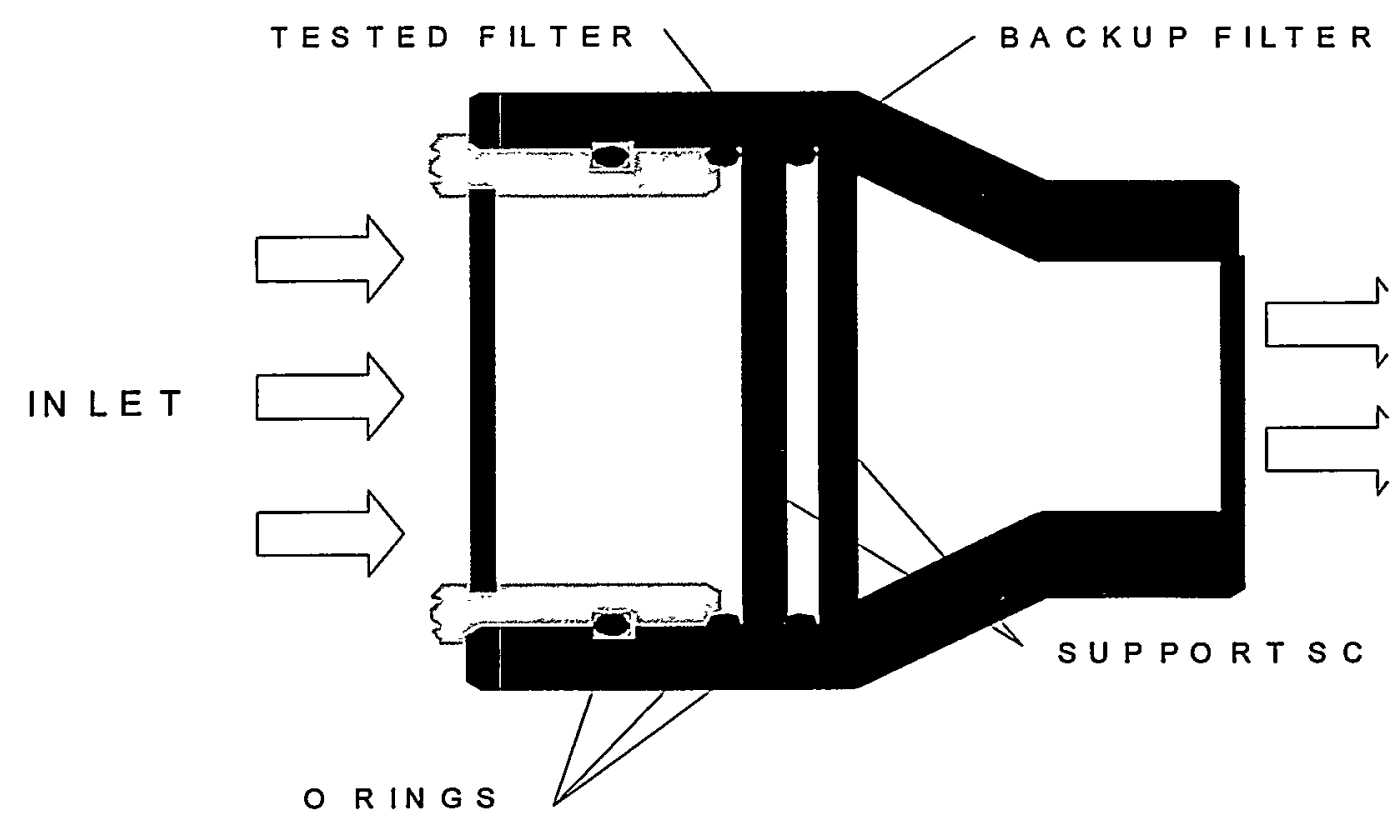

Figure 42 Schematic drawing of the special filter holder assembly used to determine the penetration of $0.3-\mu \mathrm{m}$ aerodynamic diameter monodisperse fluorescent particles through 47-mm diameter samples of filter media. 


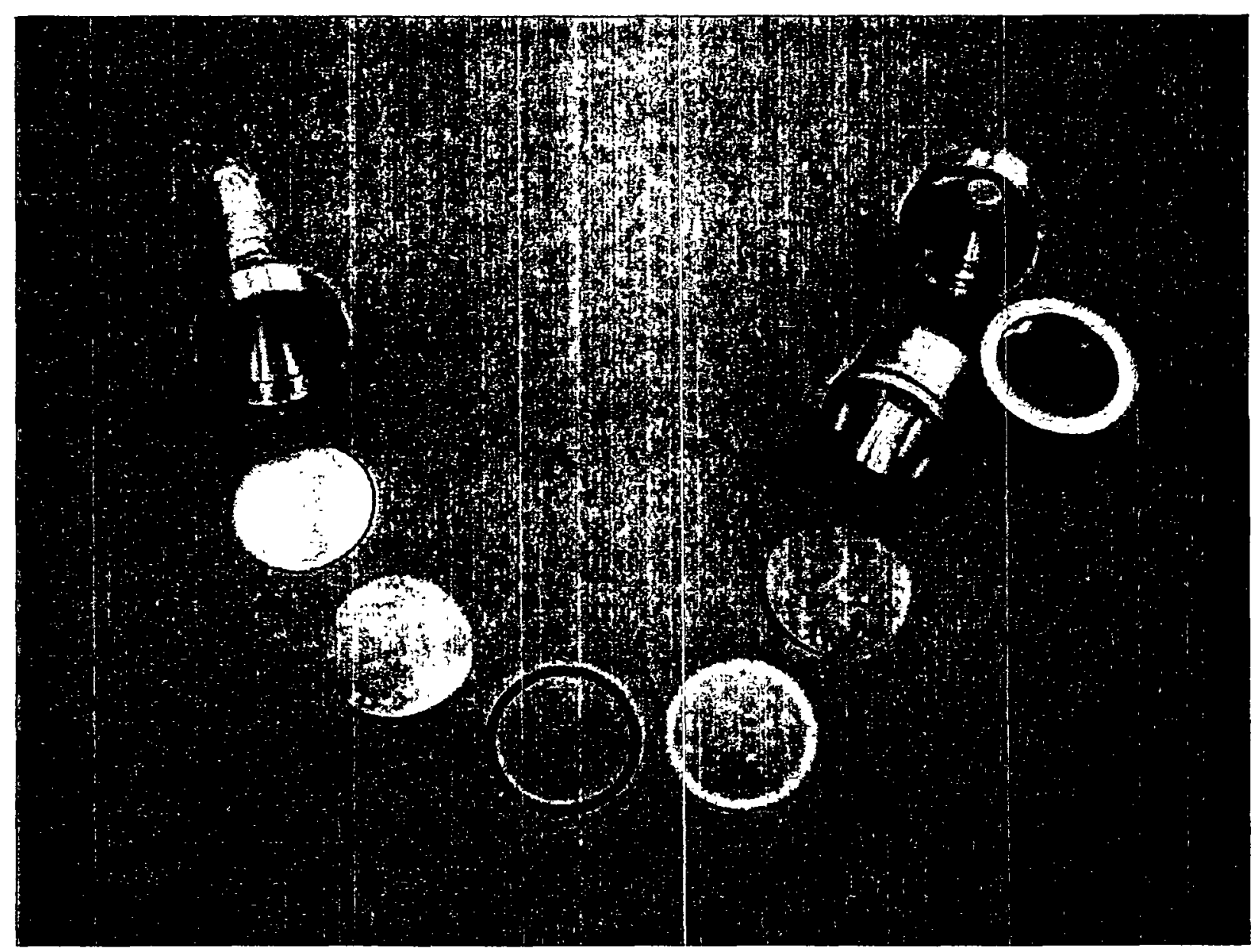

Figure 43 Photograph of the filter holder assembly for measuring penetration through filter media. From upper left to upper right, the components are the filter holder exhaust section, a stainless steel perforated-plate support screen, a high efficiency backup filter (a Millipore Fluoropore 5- $\mu \mathrm{m}$ pore Teflon membrane filter), an o-ring, a second support screen, the filter to be tested, a second o-ring (not shown), the inlet barrel, the retaining ring which screws onto the exhaust section, and an inlet adapter to connect the holder assembly to the aerosol chamber. 


\section{DATA CERTIFICATE}

\section{for AFA-RSP analytical filters}

\section{PURPOSE OF THE AFA-RSP FILTERS}

The AFA-RSP analytical filters are intended to trap radioactive aerosols and determine the isotope compositions.

\section{TECHNICAL CHARACTERISTICS AND STRUCTURE AND STANDARD COMPONENTS FOR DELIVERY}

2.1. The AFA-RSP filters are manufactured in three models, for which see the table.

2.2. The technical characteristics of the AFA-RSP filters are given in the table.

2.3. The standard components with which the AFA-RSP filters are shipped include the filtering element (in the form of a disc), which is glued to a paper support ring with a projection and is placed between protective rings, and the certificate of technical and operational data.

\section{PRINCIPLE FOR WORKING WITH THIE FILTERS}

The method for the analysis of aerosols is based on trapping the aerosol particles on the filter from a specific volume of air (gas) and subsequent measurement of the spectrum of the deposit trapped on the filter using radio frequency spectrometers.

\section{PROCEDURE FOR WORKING WITH THE FILTERS}

4.1. To take a sample, the filter kit is removed from the unfolded holder by the ring projections, and the filter is inserted in an adapter (filter holder) of the unit for taking samples and held tightly in the adapter around the outside edge of the rings.

4.2. The unit for taking samples is switched on, and the specified volume of air (gas) is pumped through the filter. It is recommended that the rate for taking the samples be set at not more than $500[?] \mathrm{cm}^{3} / \mathrm{cm}^{2} . \mathrm{s}$.

4.3. After the sample has been taken, the filter is removed from the adapter by the ring projections, the protective rings are discarded, and the filter is placed in a closed box and carried to the location where the radio frequency spectra are to be measured. In the process, the working surface of the filtering element and the support ring are not to be touched with the hands or with extraneous objects. The filter is to be handled only by the ring projections. 
4.4. At the measurement location, the filter is taken by the projection of the support ring and placed on a clean paper backing with the front side with the trapped residue up, and the projection of the support ring is cut off with scissors.

4.5. The filter on the paper backing is placed under the sensor of the radio frequency spectrometer, and the radio frequency spectra emitted by the aerosol residue trapped on the filter are measured.

4.6. The quantitative and isotope composition of the trapped aerosol ingredients are determined from the measurement data.

4.7. After the measurement has been performed, the filter is thrown into a trash receptacle for radioactive waste.

\section{PACKING AND MARKINGS}

5.1. The AFA-RSP filters are packed in paper holders, ten in each holder, and secured with rubber bands.

5.2. Ten paper holders and a data certificate are packed in each cardboard carton.

5.3. Ten cartons are packed in each bundle.

5.4. The markings are to be applied to each holder, carton and bundle.

\section{ACCEPTANCE CERTIFICATE}

The AFA-RSP analytical filters of lot 98 conform to industry standard OST $95.10052-$ 84 and have been acknowledged as suitable for use.

Date of issue 11 February 1989

Inspection Department (OTK) 


\section{TERMS OF GUARANTEE}

The manufacturer guarantees the technical properties of the filters to be as indicated, provided the packages have not been opened and have been protected against precipitation and contamination in transit and have been stored in a clean, dry place free of vapors of organic solvents and oils at a temperature not exceeding $40^{\circ} \mathrm{C}$ for 5 years.

\begin{tabular}{|c|c|c|c|c|c|c|c|c|}
\hline \multirow[b]{2}{*}{ 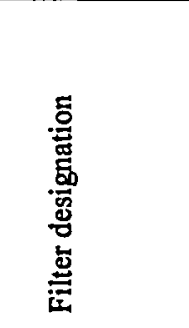 } & \multirow[b]{2}{*}{ 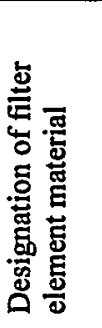 } & \multirow[b]{2}{*}{ 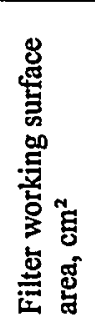 } & \multirow[b]{2}{*}{ 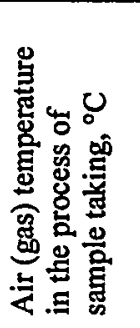 } & \multicolumn{2}{|c|}{ Relationship } & \multirow[b]{2}{*}{ 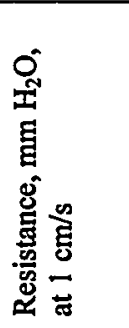 } & \multirow[b]{2}{*}{ 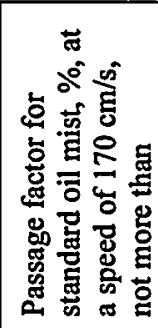 } & \multirow[b]{2}{*}{ 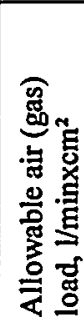 } \\
\hline & & & & 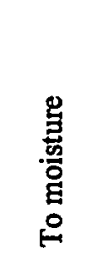 & ๑ & & & \\
\hline $\begin{array}{l}\text { AFA-RSP-2 } \\
\text { AFA-RSP-10 }\end{array}$ & LFS-2 & 10 & $\begin{array}{c}\text { from }-60 \\
\text { to }+60\end{array}$ & $\begin{array}{l}\text { Hydro- } \\
\text { phobic }\end{array}$ & resistant & $1.6 \pm 0.2$ & 10 & 20 \\
\hline AFA-RSP-20 & & 20 & & & & & & \\
\hline
\end{tabular}

Note: At a load of more than $11 / \mathrm{min} . \mathrm{cm}^{2}$, a supporting screen needs to be placed under the filter. 
Transcription of the label found on the filter boxes:

\begin{tabular}{|c|c|}
\hline \multicolumn{2}{|c|}{ ANALYTICAL AEROSOL FILTER } \\
\hline Type of AFA filter & AFA-RMP-20 \\
\hline Quantity 100 & \\
\hline Lot number & 84 \\
\hline Date of manufacture & 13 May 1994 [?] \\
\hline $\begin{array}{l}\text { Inspection Dept. } \\
\text { (OTK) stamp } \\
\text { Tech. Spec. } 95 \text { 1892- }\end{array}$ & OTK $* 14$ \\
\hline
\end{tabular}




\title{
APPENDIX B: CHARACTERISTICS OF FILTERS EVALUATED FOR USE IN SAMPLING RADIOACTIVE PARTICLES
}

\author{
Reprinted from Annex D of ANSI N13.1 (1999):
}

Glissmeyer, J. A., J. L. Alvarez, B. C Blunt, P. W. Frame, M. D. Hoover, A. P. Hull, J. M. Karhnak, A. R. McFarland, G. J. Newton, and J. C. Rodgers: Sampling and Monitoring Releases of Airborne Radioactive Substances from the Stacks and Ducts of Nuclear Facilities, ANSI/HPS N13.1-1999, Health Physics Society, McLean, VA, 1999. 
Annex D of ANSI N13.1 (1999)

(informative)

\section{Ilustration of criteria for optimizing the selection of filters for sampling airborne radioactive particles}

Table D.1 summarizes the type of information that is useful for selecting an appropriate filter for sampling airborne radioactive particles. The table includes a variety of coarse fiber, glass fiber, and membrane type filters, but does not constitute an endorsement of any particular manufacturer or filter type. Conversely, the absence of any particular filter from the example table does not constitute a rejection of that media. For general sampling applications, information is provided on durability, flow resistance, and efficiency. Information on collection of radon decay products and resolution for alpha spectroscopy is included for alpha continuous air monitor (CAM) applications. The alpha spectroscopy resolution is based on detection of the $6.0-\mathrm{MeV}$ alpha emission of polonium-218 (a naturally occurring decay product of ambient radon-222, which causes interference in instruments used to detect plutonium or uranium isotopes).

Filter efficiencies range from $>99.999$ at all particle sizes and flowrates for the Millipore type AA, $0.8 \mu \mathrm{m}$ pore size membrane filter to $<50 \%$ for the Whatman 41 cotton cellulose filter at low flowrates and small particle sizes. Typical flowrates range from as low as 4 liter/min per $\mathrm{cm}^{2}$ at $35 \mathrm{kPa}$ ( $5 \mathrm{psig}$ ) pressure drop for the Millipore Type AA membrane filter to as high as 59 liter/min per $\mathrm{cm}^{2}$ for the Millipore Fluoropore, $5 \mu \mathrm{m}$ pore size Teflon membrane filter. Resolution for alpha spectroscopy of the polonium-218 alpha emission at $6.0 \mathrm{MeV}$ ranges from as low as $350 \mathrm{keV}$ (full width at half maximum) for the Fluoropore $3 \mu \mathrm{m}$ Teflon membrane filter to greater than $1500 \mathrm{keV}$ for the Whatman 41 cotton cellulose fiber filter. The poor resolution associated with the Whatman 41 filter makes that filter unsuitable for use in continuous air monitors that are employed to detect plutonium or uranium in the presence of ambient radon decay products. In addition, although the Whatman 41 is easily dissolved for chemical analyses, it has a collection efficiency that decreases dramatically at low flowrates. The Fluoropore filters have very low pressure drop, good collection efficiency, and excellent resolution for alpha spectroscopy, but are not readily dissolved for radiochemistry. Selection of the larger pore $5 \mu \mathrm{m}$ Fluoropore filter over the $3 \mu \mathrm{m}$ pore option provides a substantial improvement in flowrate, with only a modest decrease in sampling efficiency and resolution for alpha spectroscopy.

As new filter types become available, comparisons such as these can be made by the user to ensure that appropriate filter types are selected for sampling radioactive aerosols.

See attached word perfect file of our filter table. 


\section{Distribution}

No. of

Copies

OFFSITE

2 Ukraine Academy of Technical Sciences, Radiation Protection Institute

ATTN: I. A. Likhtarev

O. A. Bondarenko

2 Chornobyl Nuclear Power Plant Object Shelter

ATTN: A. A. Korneev
No. of

Copies

ONSITE

48 Pacific Northwest National Laboratory

D. P. Couch K7-74

S. D. Dossett $\quad$ P7-75

B. F. Gore $\quad$ K7-80

M. E. Hevland K2-20

E. E. Hickey ' $\quad$ K3-56

R. A. Hoover K3-53

N. A. Jackson K7-74

D. K. Kreid K7-74

W. J. Martin K3-54

J. C. McDonald K3-53

R. L. Moffitt K7-74

J.K. Neal P7-57

B. W. Smith K8-46

G. R. Petersen K7-74

K. L. Soldat K3-53

G. J. Vargo (25) K3-56

J. C. Wiborg K7-74

Information Release Office (7) K1-06 